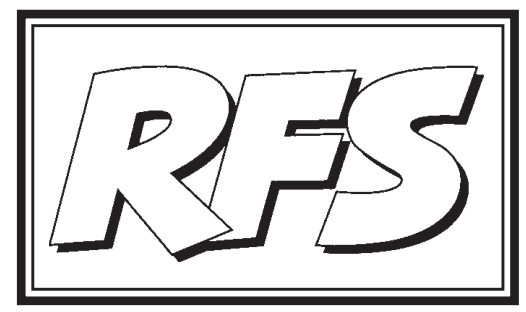

Revista de Fomento Social, 59 (2004), 129-176

\title{
La sociedad civil ante los procesos de integración en América Latina
}

(Palabras Clave: Sociedad CiVlL, Procesos de integración, AmÉrica latina. KEY WORDS: CIVIL SOCIETY, INTEGRATION PROCESSES, LATIN AMERICA)

\section{Introducción}

Los procesos de integración regional en América Latina no constituyen, por sí mismos, una novedad en la lucha permanente que estas sociedades llevan a cabo por la búsqueda de la modernización y el desarrollo. Lo que sí aparece como primicia es el panorama sociopolítico sobre el que se conjugan los nuevos procesos, ahora generalizados por afectar a todos y cada uno de los países de una u otra manera. Dentro de este nuevo espacio encontramos

1 Licenciado en Geografía e Historia por la UNED. Doctorando en el Programa de Doctorado: Planificación, dirección y entorno económico-social de la empresa. ETEA. 
elementos cuya intervención puede proporcionar escenarios alternativos que modifiquen el rumbo de los acontecimientos, cautivos hasta ahora de las tradicionales ataduras impuestas por su vulnerabilidad económica. De entre ellos cabe destacar la formación de un incipiente movimiento ciudadano en el seno de la sociedad civil, gestado al amparo de la democratización de los Estados y de la globalización tecnológica, que exige la participación y el derecho a hacer oír su propia voz.

Analizar el papel de la sociedad civil en los procesos de integración regional en América Latina constituye, pues, un ejercicio novedoso que requiere el tratamiento de fuentes dinámicas escasamente catalogadas, ya que no existen referencias bibliográficas o académicas anteriores. Desde el principio, este trabajo tuvo plena conciencia de esta dificultad, haciendo constar dicha singularidad por anticipado, si bien los resultados han sido enteramente satisfactorios.

En un principio, una primera definición de sociedad civil sería la de aquel espacio de la esfera pública donde grupos auto-organizados, movimientos e individuos relativamente autónomos del gobierno, intentan articular valores, crear asociaciones y solidaridades, así como hacer avanzar sus intereses ${ }^{2}$. Estas organizaciones no formarían parte en ningún caso del gobierno, ni de un sistema político (partidos), ni tampoco tienen un fin económico como objetivo principal (empresas). No obstante, para que la sociedad civil alcance la relevancia suficiente, necesita relacionarse con estos dos ámbitos, además de con el Estado y los ciudadanos en general. Está, por tanto, plenamente integrada en el sistema.

El primer problema surge al pretender acercarnos al conocimiento de la sociedad civil latinoamericana. No es tarea fácil, ya que escasean los trabajos académicos que puedan dar una idea cercana de su perfil, entre otras cosas porque se trata de un fenómeno incipiente y en formación, que sólo parece despegar con el crecimiento -parece que definitivo- de las democracias en todo el continente. Por otro lado, los actuales procesos de integración regional en América Latina, revitalizados desde los noventa, tampoco cuentan con evaluación sistémica alguna, debiéndonos servir de una comparación temporal e histórica con los desarrollados desde los años sesenta, que sí cuentan con estudios y análisis suficientes. Estos últimos, no obstante, carecen de estudios analíticos sobre la relación del binomio

2 Christian Freres, (1997), p. 37. 
sociedad civil-integración regional, o sobre la incidencia y participación de una sobre la otra, lo que no deja de tener relevancia, si tenemos en cuenta que entre los motivos del fracaso de los primeros movimientos integradores latinoamericanos se detecta un tratamiento excesivamente economicista de la integración, alejado de los objetivos sociales que toda acción económica e institucional debe llevar consigo.

Como ya hemos apuntado más arriba, hay que acudir entonces a fuentes alternativas y novedosas, casi todas gracias a internet, que, además de ayudar a resolver algunos interrogantes, proporcionan momentos de intensidad y entusiasmo. Así, además de la bibliografía preceptiva, se ha hecho uso de fuentes tan variopintas como las páginas webs de los diarios de noticias digitales -en gran número y de casi toda América Latina-, las de multitud de asociaciones y organizaciones no gubernamentales, las de instituciones oficiales, sindicatos y otros.

Para conocer las sociedades latinoamericanas hemos de recurrir a bibliografía especializada de la mano de la sociología, descartando cualquier tipo de conocimiento previo -por simplista y sesgado- que emane de nuestro bagaje académico. Nos encontramos entonces con unas sociedades desconocidas, alejadas en gran medida de los arquetipos prefijados por nuestros conocimientos históricos. No se puede entender el papel de la sociedad civil si se desconoce la sociedad de la que nace. Aún a riesgo de extendernos, parece conveniente exponer de forma resumida los caracteres configuradores de esas sociedades.

En la segunda parte de la exposición, al analizar los comportamientos y los mecanismos de actuación de la sociedad civil, se puede comprobar lo novedoso e innovador de sus métodos participativos e informativos, sobre todo en lo que concierne a foros y asociaciones mediante el amplio despliegue abierto de páginas webs en internet. Esta fórmula proporciona gran dinamismo y un elevado nivel participativo, permitiendo la comunicación entre diversos grupos sociales -nacionales e internacionales- que se organizan como frente común unidos por sus afinidades ideológicas o solidarias. También resulta novedoso las concentraciones y manifestaciones civiles que se vienen realizando en torno a las cumbres de jefes de Estado o de gobierno. Organizadas como jornadas festivas y reivindicativas, su mayor valor reside en la demostración de su poder de convocatoria. La globalización informativa está, pues, creando nuevas formas de relación y reivindicación propias de la época actual; nunca antes se había conseguido aglutinar y cohesionar tal 
diversidad de contingentes. Por todo ello, resultaba interesante incluir un apartado que recogiera estas nuevas formas de expresión y participación.

De esta manera, el trabajo está dividido en tres partes. La primera es descriptiva y pretende resumir una caracterización de la sociedad de América Latina alejada de tópicos y centrada en la consecución de una definición explicativa de su comportamiento. La segunda parte es eminentemente especulativa, procurando aislar el núcleo de la proposición, esto es, el papel desempeñado por la sociedad civil en los diversos procesos de integración latinoamericanos. En ella se intenta responder a algunas preguntas fundamentales y se presenta el nuevo escenario participativo que se ha venido configurando en torno a las nuevas manifestaciones de la sociedad civil. Finalmente, la tercera parte recoge una serie de conclusiones que, modestamente, ha sugerido la realización de este estudio.

\section{La Sociedad latinoamericana}

\subsection{Una visión de la sociedad latinoamericana}

Caracterizar la sociedad de América Latina requiere tener en cuenta inicialmente al menos dos aspectos fundamentales de los cuales debemos partir. En primer lugar, encontramos la complicación de enfrentarnos a una vasta unidad territorial que se extiende desde el sur de los ríos Grande y Bravo hasta el Cabo de Hornos, allá por las frías costas de la Tierra del Fuego, incluyendo las islas del Mar Caribe y ocupando aproximadamente unos 22 millones de kilómetros cuadrados de ambos hemisferios. Contiene 25 repúblicas y 14 territorios no independientes ${ }^{3}$ que dan cobijo a un mosaico étnico diverso de más de 500 millones de personas ${ }^{4}$, en torno al $10 \%$ de la población mundial. Esta complejidad configura una masa heterogénea a nivel sociológico, político, económico, demográfico y étnico que pone en tela de juicio las consideraciones generales que toda caracterización lleva consigo.

En segundo lugar, nos estamos refiriendo a unos territorios con grandes niveles de homogeneización cultural debido a su pasado colonial común.

3 Raúl Grien, (1994), pp. 98-99

4 El Estado del Mundo 2001. Akal, (2000), pp. 365-400. 
Esta homogeneidad de las culturas regionales afecta a su lengua, religión y costumbres -fundamentalmente-, factores todos que inducen a cierto perfil unificador a la hora de ofrecer una estimación de sus valores civilizadores de conjunto.

Ambos factores aparecerán en todo momento insertados en las valoraciones que aquí se hagan, pero nunca desde un punto de vista simplista, sino más bien como criterio de demarcación que habrá de tener presente toda evaluación generalizadora.

Tradicionalmente, sobre todo a este lado del Atlántico, se había venido aceptando una visión de la sociedad latinoamericana en la que permanecían vigentes los rasgos acuñados por la herencia colonial española en sus manifestaciones principales. Era ésta la concepción de una estructura social clasista, con la población indígena como elemento de marginación, un sistema político corrupto e ineficaz, ocultando bajo la legalidad democrática el mantenimiento del poder por los de siempre, y una desigualdad económica paradigmática como principales elementos identificadores. A estas características estructurales se venía añadiendo también la intromisión secular de dos poderes fácticos de gran potencia: el ejército y la iglesia católica. Todo ello configuraba un conjunto burdamente simplificador, que, si bien contiene algunas dosis de realidad, respondía más bien a un discurso esencialmente superficial, que enlaza con el tradicional sentimiento de pesimismo noventayochista y con una mordaz insistencia en el mimetismo entre nuestra propia sociedad decimonónica y esta pretendida realidad social latinoamericana.

Una visión más actualizada de la sociedad de América Latina ofrece elementos muchos más ricos y complejos que cuentan con una larga trayectoria civilizadora.

A partir de la segunda mitad del siglo XIX, las estructuras sociales de los países latinoamericanos sufrieron grandes cambios. La población se duplicó, gracias al aporte demográfico de las migraciones europeas desde finales de siglo. La inmigración será la propulsora de la modernización de las sociedades latinoamericanas, sobre todo en el Cono Sur. Esta avalancha de contingentes modificó el edificio social que se mantenía desde la independencia, mero continuador del colonial, haciendo surgir nuevas clases sociales gracias al acceso de los inmigrantes a la industria y al comercio, que llevará a la creación de una clase media y un proletariado industrial antes inexistente. Será también el catalizador de la progresiva decadencia de las oligarquías, arrinconadas ahora en el medio rural del que proceden, aunque conservando altas cotas 
de poder de la mano de la educación, el ejército y la iglesia.

El siglo XX contempló una notable evolución que termina con la definitiva modernización de las estructuras sociales. Durante el primer cuarto de siglo, el modelo exportador se erige en adalid de prosperidad favorecido por la coyuntura devenida por la Gran Guerra. Paralelamente, las sociedades van tomando un nuevo rumbo en pos de la modernidad occidental. Nace un incipiente antiimperialismo como respuesta intelectual a la sempiterna dependencia económica, se manifiestan los primeros movimientos estudiantiles e indígenas, las clases medias empiezan a ocupar una posición dominante en el espacio político y, definitivamente, parece tomar forma el incipiente movimiento obrero.

La crisis de 1929 asesta un duro golpe sobre las tradicionales economías exportadoras, marcando un punto de inflexión fundamental para el futuro del continente. Se produce entonces una importante transferencia de recursos desde el sector primario-exportador al sector industrial, que queda consolidado tras la Segunda Guerra Mundial con la adopción generalizada de lo que se viene a denominar "el proceso de industrialización por sustitución de importaciones", avalado por las tesis estructuralistas de la CEPAL (Comisión Económica de las Naciones Unidas para América Latina). Ante este nuevo escenario, los actores sociales inician una reorganización en torno a la nueva dimensión que adquieren sus respectivos papeles.

Se pudo observar una cierta e importante integración entre las llamadas burguesías nacionales y las oligarquías terratenientes y exportadoras. Las clases medias se reafirman, fortalecidas gracias al flamante papel de burócratas y tecnócratas a partir del aprovechamiento de la gestión y administración del nuevo Estado interventor. Pero el intento de industrialización sólo alcanza el éxito cuando es capaz de aglutinar a los diferentes grupos sociales en un equilibrio precario y bastante inestable. El control de la conflictividad laboral de los obreros industriales -sometidos a una explotación palpable- sólo se realizará mediante la irrupción de los populismos y sus eficaces políticas asistenciales y de previsión social. Por otro lado, el encarecimiento del consumo, como consecuencia del proteccionismo que traía consigo la adopción de la nueva estrategia económica, obligó a recurrir al discurso nacionalista para hacer digerir tan costosa política.

El fracaso económico del proceso de industrialización por sustitución de importaciones y la consiguiente incapacidad para tomar el camino definitivo hacia el desarrollo, marcarán las convulsiones sociales y políticas 
permanentes a las que se ha visto sometido la mayor parte del continente durante la segunda mitad del siglo XX. Los efectos de las crisis respectivas han hecho mella en el seno de las diferentes sociedades, quedando en la actualidad sumidas en serios problemas de gobernabilidad, corrupción, desigualdad en la distribución de la renta y de la riqueza así como de altas dosis de dependencia económica.

La aparición y participación de nuevas manifestaciones y aportes sociales de grupos antes marginados-como las comunidades indígenas-o inexistentes -como los colectivos feministas y las organizaciones no gubernamentales-, son los hechos más relevantes de los últimos años. Tampoco hay que olvidar los elementos más negativos surgidos de los efectos desestabilizadores -económicos y políticos-de las últimas décadas del siglo XX; concretamente podríamos citar el narcotráfico, la violencia y los masivos procesos de emigración hacia Estados Unidos o Europa.

Las dificultades de toda índole que últimamente vienen arrastrando estas sociedades latinoamericanas, dentro de una definitiva configuración mundial globalizada, obligan a preguntarse en qué instante del proceso de formación de una sociedad moderna y articulada se encuentran, ya que de ello dependerá buena parte de las soluciones que se articulen para superar tan comprometida situación. Tanto es así, que de no resolver la decisiva formación de una sociedad civil fuerte, integrada, articulada y con el poder necesario para cambiar su propio futuro, se verá abocada a un dualismo esta vez sí que verdaderamente simplista y fatal: el de una sociedad de ricos y pobres.

\subsection{El concepto de Sociedad Civil}

El concepto de sociedad civil es un debate muy en boga actualmente. A la evidencia de su dificultad en la definición se añade la continua ampliación de contenidos que últimamente se vienen produciendo, fundamentalmente como consecuencia de las aportaciones y el desarrollo de las organizaciones no gubernamentales para el desarrollo y la cooperación internacional. En su complejidad intervienen una multitud de posiciones filosóficas, culturales e ideológicas.

Partiendo de la definición expresada en la introducción, el concepto de "sociedad civil" ha sido utilizado de manera muy amplia para definir todo aquello que no es Estado, y englobaría a toda la población. Algunos autores consideran este concepto como una ficción metodológica, ya que lo que 
verdaderamente existe son diversas sociedades nacionales que, de ninguna manera, podríamos considerar como una totalidad. Estas sociedades civiles han sido las destinatarias pasivas de los diversos procesos integradores en América Latina. Sólo aquellos sectores verdaderamente organizados -aunque carentes de representatividad- han desarrollado acciones tendentes a la búsqueda de alternativas a sus problemas.

Como antecedente, la sociedad civil aparece en Europa de la mano del nuevo Estado moderno, en el siglo XVIII, con constantes altibajos que coinciden con la narración de la historia contemporánea. Para unos, su papel fue fundamental en la formación de los Estados democráticos. Otros, en cambio, argumentan que es fruto de ese desarrollo político. Además de la democracia, existen factores que han contribuido a conformar lo que luego se ha denominado como sociedad civil, dependiendo su alcance e influencia del nivel de desarrollo alcanzado. Factores como la alfabetización masiva, la idea de nación, la proliferación de los medios de comunicación, la libertad económica, la igualdad de la mujer y la creciente importancia de las organizaciones voluntarias.

De entre las organizaciones de la sociedad civil que han adquirido mayor protagonismo, la más antigua es la Iglesia, sea esta católica o protestante, con clara vocación universalista y misionera. En Europa surge también un segundo grupo de organizaciones a partir del proceso industrializador que se relacionan con sindicatos y partidos políticos. Otros grupos se vinculan al nacimiento y consolidación de amplios sectores de clase media, sobre todo en Europa y EEUU, como bien pudieran ser las asociaciones de profesionales, culturales, académicas, sanitarias o las fundaciones. Finalmente, aparecen organizaciones con orígenes difusos pero con creciente importancia. Son aquellas formadas por las organizaciones no lucrativas y por las denominadas organizaciones no gubernamentales, que centran su atención en el campo de la cooperación, el desarrollo, la acción social o los valores medioambientales.

En la actualidad, espoleada por la vorágine globalizadora, se ha abierto camino la idea de una renovación de la cultura cívica muy preocupada por los derroteros que está tomando la estrategia geopolítica mundial. Un aspecto fundamental de este proceso es la relevancia económica producida en los mercados del sector servicios por la irrupción de estas organizaciones de la sociedad civil en las últimas décadas. Bajo el epígrafe de "tercer sector" o "sector no lucrativo", se canaliza un flujo económico muy pujante de ca- 
rácter internacional, cuyos gastos alcanzaron un 4,6\% del PIB mundial en 1995 y que fue capaz de generar 19 millones de empleos remunerados, lo que supone un $5 \%$ del empleo total no agrario. Estas cifras equivaldrían a la octava economía mundial ${ }^{5}$. No obstante, se detectan grandes variaciones en el tamaño entre países y regiones, registrándose un menor volumen para América Latina, donde Argentina, Perú, Colombia, Brasil y México -por este orden- generan un mayor nivel de recursos.

No cabe duda que la pérdida de peso económico del Estado en las últimas décadas es una de las causas de esta notable incidencia del sector. A la reducción del "Estado del bienestar" producido en los países del norte, tendríamos que sumar la ineficacia en la gestión del Estado en los países del sur, sobre todo en lo referido a políticas de desarrollo. Esta situación ha provocado la reacción de la ciudadanía, abocada a hacer frente a múltiples problemas relacionados con el desarrollo, el bienestar social o el medio ambiente.

A la hora de caracterizar a la sociedad civil latinoamericana, la heterogeneidad sería el principal rasgo a tener en cuenta. Esta falta de homogeneidad afecta a su organización, su visión diferenciada de los diversos problemas latinoamericanos, sus propósitos, sus intereses o sus proyectos. Es importante resaltar, debido al objeto de este estudio, una singularidad que afecta directamente al tema en cuestión. En América Latina, el concepto de sociedad civil adquiere un matiz más amplio, de mayor alcance. Así, en muchos países se incluye a las empresas como miembros de la sociedad civil, lo que no ocurre en Europa. Igualmente es destacable el papel que juega la vida política y social, en un claro intento de asociar a la sociedad civil con la calidad de la democracia, aún vulnerable y por consolidar. En este sentido, las diversas organizaciones de la sociedad civil latinoamericana se han venido caracterizando por una tensa relación con el Estado, fruto de la crítica generalizada a la escasez y pésima calidad de los servicios que éste ofrece a su ciudadanía.

En América Latina están presentes la mayoría de los grupos y organizaciones ya descritos en párrafos anteriores, desde las tradicionales organizaciones benéficas a las más recientes organizaciones populares y organizaciones no gubernamentales. Entre estas últimas, cabe destacar la creciente importancia de los movimientos indigenistas, resultado de la paulatina integración social de estas capas de población antes muy relegadas. Su potencial es un

5 L. Salamon, H. K. Anheier, R. List, S. Toepler, W. Sokolowski, y colaboradores, (2001), pp. 26-29. 
factor de primera magnitud a tener en cuenta en el futuro, debido a que en ciertas zonas constituyen la población mayoritaria. De esta trascendencia se ha hecho eco la historia reciente de algunos países, llegando a forzar las dimisiones de los presidentes ecuatoriano (año 2000) y boliviano (2003). A grupos de extracción eminentemente indígena como los cocaleros bolivianos, los zapatistas mexicanos o el movimiento patchakuti ecuatoriano-este último erigido finalmente como partido político-, se les unen otros movimientos de marcado carácter reivindicativo como los movimientos brasileños de los sem terra (sin tierra) y los sem teto (sin techo), los piqueteros argentinos, los bolivarianos de Venezuela o los rebeldes Humala de Perú. Todos ellos son ejemplos de nuevos actores sociales y políticos que reclaman una participación efectiva en las decisiones de sus gobiernos respectivos, desafiando -en algunos casos- al poder tradicional.

Otros grupos de relevancia son las organizaciones no gubernamentales y de desarrollo, muy centradas en los aspectos de la colaboración y con un marcado acento en el carácter voluntario y participativo. En la actualidad, parecen haber alcanzado una mayoría de edad que está estrechamente relacionada con la eclosión globalizadora, encontrando su principal asidero en manifestaciones reivindicativas basadas en el desarrollo global y equilibrado como el Foro Social Mundial de Porto Alegre.

Una de las deficiencias que lastran el proceso de configuración de una sociedad civil latinoamericana fuerte, radica en la falta de representatividad y legitimación de los diversos grupos. La carencia de una estructura organizativa, de redes sociales vertebradoras capaces de canalizar y de gestionar los flujos de intereses y de opinión entre los miembros de la sociedad y los respectivos gobiernos en torno a mesas de concertación, aparecen como verdaderos frenos a dicho proceso. La creación de plataformas que aporten un estatuto de legitimidad a los diversos portavoces, dentro del actual clima de democratización, debe establecerse como requisito indispensable y como argumento para la consecución de compromisos entre el gobierno y la sociedad civil. La institucionalización de la participación social será el primer paso hacia consolidación democrática.

\subsection{Una estructura social compleja dualizada}

En el apartado anterior, hemos visto alguna de las cualidades y debilidades fundamentales de la sociedad civil latinoamericana que vienen a incidir en 
los procesos de integración regional. Esta caracterización, como no podía ser de otra manera, se relaciona directamente con la estructura social de la que nace. Por ello, sin pretender realizar un análisis exhaustivo de las sociedades latinoamericanas -cosa que, por otro lado, queda totalmente ajeno a los objetivos de este trabajo-, sí podemos intentar acercarnos a ellas en la búsqueda de una explicación que nos ayude a entender la posición y la reacción de estas ante estímulos como los procesos de integración regional que aquí estamos estudiando.

Si hay un rasgo que defina el componente principal de la Estructura social latinoamericana es la desigualdad. Persistente a lo largo de la historia, se está convirtiendo en un problema creciente en las últimas décadas, debido a la deriva social que los graves problemas económicos por los que atraviesan la casi totalidad de los países latinoamericanos están causando. Esta profunda desigualdad se alimenta de un enorme crecimiento demográfico merced al mantenimiento de una elevada tasa de natalidad y por un constante flujo de población rural hacia las ciudades, convertidas en verdaderas megalópolis que se ven desbordadas ante tan enormes contingentes e incapaces de gestionar y garantizar un mínimo de servicios municipales.

Otro rasgo definitorio de la estructura social de América Latina es su complejidad. Los últimos trabajos sociológicos sobre el continente se están haciendo eco de nuevos elementos de análisis social que hasta ahora no se habían valorado en su justa medida, como el proceso de norteamericanización o los efectos causados por la emigración en muchas regiones. Al mismo tiempo, el carácter modernizador de las sociedades latinoamericanas, rasgo este característico durante todo el siglo XX, va configurando un panorama cada vez más heterogéneo, unas sociedades en constante mutación.

La configuración social de América Latina resulta de una estrecha relación con su modo específico de desarrollo. Este modelo ha venido impuesto del exterior, con la complicidad de las clases dirigentes, y sin contar con las poblaciones. Todo ello ha creado un capitalismo limitado y dependiente, un modo específico de desarrollo que puede definirse a la vez por la formación de una sociedad industrial y por los límites impuestos a esa formación por el capitalismo dependiente ${ }^{6}$. La especificidad de su desarrollo económico ha fomentado la dualización a través de un proceso desvertebrador en el que conviven las empresas modernas con las tradicionales; las empresas

6 A. Touraine, (1989), p. 35. 
extranjeras con las nacionales; y los que participan en la producción y en el consumo moderno con los que quedan excluidos de ellos. Un desarrollo de tipo postcolonial con un importante papel de las burguesías capitalistas extranjeras como introductoras de los principales cambios socioeconómicos, pero que no participan en el juego sociopolítico, que depende de los protagonistas del potente Estado nacional. Todo ello ha creado un juego de relaciones en las que los diversos componentes de una misma situación socioeconómica nada tienen que ver los unos con los otros por su diferenciada situación.

Nos encontramos entonces ante unas clases sociales muy débiles y divididas, con muy poca influencia política. Los privilegiados disfrutan de un sistema económico cuyos procesos fundamentales les son ajenos por su dependencia exterior; los desfavorecidos, pertenecientes a los sectores agrícolas, tradicionales, y en general, a todos aquellos que no poseen titularidad pública, apenas participan de los intercambios económicos y en los sistemas políticos nacionales. No existe una adscripción social o profesional, ni sentimiento colectivo de clase, ya que no han sido éstos los principales artífices sociales. Tampoco existe homogeneidad cultural y política dentro de cada categoría social, ya que -a diferencia de la sociedad europea- no ha habido una evolución económica sucesiva: sociedad rural, mercantil, industrial o postindustrial, sino que todas han estado solapadas al mismo tiempo.

El modelo de desarrollo latinoamericano se diferencia claramente del que domina los países centrales. Si estos dan importancia a valores civiles como el interés, la racionalización, la representatividad o las clases sociales, en América Latina los modelos de desarrollo se identifican con un proyecto que es, a un tiempo, social y nacional. Es el Estado el que ejerce de integrador entre excluidos y privilegiados, gracias a una clase media en rápido desarrollo y con gran capacidad de movilización entre los sectores populares. En América Latina no existe una separación clara entre la sociedad civil y el Estado. El Estado interviene en todos los ámbitos de la sociedad, sin que ésta responda a las iniciativas de otros sectores sociales, a los que no se siente vinculada ${ }^{7}$.

La clase media ha jugado un papel principal en aquellos países en los que la industrialización y la intervención del Estado la propiciaron. Pese a su debilidad en el conjunto de América Latina -inexistente en algunos paí-

\footnotetext{
7 A. TOURAine, (1989), p. 54.
} 
ses-, ha sido la verdadera impulsora del desarrollo y de la modernización en virtud de una presencia obligada en el juego político durante el siglo XX. Si esta participación en la vida pública y cultural es primordial, no se puede decir lo mismo de su valor económico. Un estrecho vínculo con el Estado va a ser el verdadero artífice de su creación como elemento de control del modelo nacional de desarrollo. En muchos países, el sector público representa la mayor parte del mercado laboral, con gran peso sobre el empleo urbano formal.

Es una categoría social formada, partidaria de las mejores virtudes de la tradición cultural de occidente, que tiene en el Estado a su principal instrumento de liberación de las ataduras tradicionales propiciadas por las oligarquías y sus apoyos políticos y religiosos. Pero se interesa poco por la industria o los negocios -salvo, quizás, la excepción de México-, lo que le resta potencial. La segunda mitad del siglo XX ha marcado su apogeo y posterior declive. La estrecha vinculación con el Estado le ofreció una época de esplendor con la creación del Estado nacional-popular y las políticas económicas intervencionistas y proteccionistas. El declive de éste a finales de siglo ha mermado claramente su influencia, siendo la principal perjudicada en el desmantelamiento del Estado propiciado por las políticas de ajuste estructural. En la actualidad ha dado lugar a una segmentación social en la que destaca una nueva clase media de técnicos vinculados a las grandes empresas industriales y financieras, generalmente extranjeras. Por otro lado aparece una clase media independiente en vías de empobrecimiento que tiende a caer en el sector informal. Entre ambas, queda una clase media administrativa en la que destacan los profesionales asalariados, que pierden influencia y caídas de renta constantemente.

Las oligarquías vieron cómo disminuía su influencia paulatinamente debido a los procesos de industrialización y urbanización. En la actualidad resulta difícil considerarla como la clase dirigente, máxime si tenemos en cuenta que gran parte de las inversiones están en manos extranjeras o del Estado, lo que pone de manifiesto su escaso papel rector. Su actividad se centra en la propiedad rural, el comercio y la banca, integrando grupos diversos, desde exportadores hasta empresas urbanas, comerciales o financieras, pero la mayoría ligados a sectores extranjeros, verdaderos dominadores de la economía. El oligarca se ha convertido en un especulador que apenas se siente vinculado con sector alguno de la producción. Sigue siendo un grupo social cerrado, pero ya no actúa como clase con la coherencia y unión que lo hacía en el pasado, sino que busca única y exclusivamente su enriqueci- 
miento, sabedor de la pérdida de hegemonía sociopolítica y de los principales resortes del poder en manos del populismo. Hoy en día, no existe ningún lugar en América Latina donde se correspondan directamente los intereses económicos y los políticos, las tendencias autocráticas de las clases más poderosas se han debido plegar ante el empuje imparable de la democracia. Para llevar a cabo el ejercicio del poder deben coaligarse con grupos cuyo interés sea el reforzamiento del Estado antes que la defensa de los intereses de clase. Así, su influencia actual es limitada.

Las clases obreras estaban llamadas a ejercer un papel protagonista en las sociedades latinoamericanas debido a los procesos de industrialización que se llevaron a cabo en algunos países. Sin embargo, el movimiento obrero ha jugado siempre un papel muy secundario y subordinado, que se ve refrendado -por ejemplo- en la inexistencia de partidos políticos de clase en casi toda América Latina (excepto Chile). A pesar de la importancia del asociacionismo sindical en algunos países, la clase obrera nunca alcanzó un nivel de vida aceptable y generalizado. Su debilidad se ve acentuada por la dualización y por la heterogeneidad estructural de la economía donde se puede encontrar desde la industria de exportación, pasando por la industria moderna de capital público o extranjero, la industria tradicional de capital nacional y la industria del sector informal. Esta variada tipología hace muy difícil organizar una estrategia de actuación de masas. La diversidad de industrias y empresas llevan a una concepción diferenciada de cada grupo obrero, con una muy diversa variedad de salarios y coberturas de prestaciones sociales. La enorme importancia económica del sector informal distorsiona y separa los intereses de clase: de los que tienen empleo a los que no, de los obreros del sector formal a los marginados del sector informal, de los que participan en el sistema a los que no lo hacen.

El papel de los sindicatos es muy diferente al que conocemos. Su acción se dirige principalmente contra el Estado, en lugar de hacerlo contra las empresas. Su objetivo es la apertura política y el aumento de influencia en el sistema, antes que una movilización de clase. Es un hecho que deriva de la escasas garantías políticas que tradicionalmente otorgaba el Estado a las clases populares, pero que en la actualidad no tienen un verdadero sentido si no es la excesiva dependencia y manipulación que de los sindicatos hacen los partidos políticos.

Los trabajadores agrícolas ofrecen unos rasgos característicos propios que le alejan de toda equiparación con otras sociedades modernas, y con el 
resto de los sectores productivos latinoamericanos, viniendo a confirmar la complejidad social ante la que nos encontramos.

Se mantiene, en buena parte del continente, el predominio de las formas no capitalistas de organización del trabajo. Habitualmente, el colono trabaja para la hacienda o plantación y divide su tiempo con la explotación minifundista de propiedad particular, que le da para autoabastecerse y para los mercados locales. Su estatus está, pues, a caballo entre el proletariado agrícola y el pequeño campesinado. Es un sistema mixto en el que no existe correspondencia entre producción y mercado. No hay establecidas unas relaciones sociales de producción de tipo capitalista, aunque existen diferenciaciones regionales.

Esta fórmula, tantas veces en crisis aunque persistente, permite la asociación productiva del latifundio y del minifundio, de la explotación capitalista y de la no capitalista. No cabe duda de que se trata de una relación funcional, en la que la existencia del minifundio permite el mantenimiento de unos bajísimos costes salariales en las plantaciones latifundistas.

Así, encontramos a un sector agrícola que no se incorpora en su totalidad a la economía de mercado, con una difícil diferenciación entre campesinos independientes y proletariado agrícola -si bien es más numeroso el primero que el segundo-, con tasas de productividad muy bajas por su condición minifundista y tradicional, a la vez que con un alto índice de desempleo por su marcado carácter de subsistencia. Ante ese panorama, resulta evidente la escasa vertebración y unificación sectorial al no existir pautas de comportamiento comunes.

Finalmente, se configura crecientemente un sector informal urbano de producción, en clara correspondencia con el permanente proceso migratorio del campo a la ciudad que se ha venido llevando a cabo durante la mayor parte del siglo XX y con el mantenimiento de las altas tasas de natalidad. Este sector aglutina a un importante contingente de trabajadores sin formación ni cualificación, subempleados o en paro, víctimas de pésimas condiciones de alojamiento y alimentación, y que participan muy poco, o de manera ocasional, en la vida social y política.

El incremento constante y los efectos perversos de esta economía sumergida ha configurado una marginalidad muy heterogénea, alcanzando incluso a categorías profesionales de reconocido prestigio. Su importancia es considerable, incluso se ha instalado en el comercio y las pequeñas empresas. 
Diversos estudios elevan a más de un 10\% de la población total afectada por este tipo de economías, de las cuales resulta difícil salir. El crecimiento económico de las últimas décadas no ha impedido la expansión de este sector, demostrando a las claras la debilidad de las economías latinoamericanas y la insuficiente capacidad de absorción de la mano de obra por parte de los nuevos agentes económicos. En muchos países, el subempleo supera al empleo formal, agravando las desigualdades y dando lugar a la proliferación de factores de exclusión social.

Volviendo a la propuesta inicial con la que abríamos este apartado, tras este somero recorrido por la geografía social latinoamericana, podemos convenir que la debilidad que muestra la sociedad civil en América Latina no es sino el resultado de una sociedad muy compleja cuya principal carencia es la práctica ausencia de actores sociales con autonomía suficiente. La creciente desigualdad, motivada por la crisis social y económica, se convierte en un obstáculo más que salvar en el camino hacia la construcción social y la democratización como fin último. Los problemas de gobernabilidad de la mayor parte de América Latina parecen girar en torno a estos dos grandes logros: la lucha efectiva contra la desigualdad y la constitución definitiva de los diversos grupos sociales con capacidad de acción y representación.

\subsection{La crisis institucional permanente}

La historia social y política de América Latina a lo largo del siglo XX ha estado jalonada de convulsiones permanentes. Se diría que ha andado por el siglo a la búsqueda de una madurez social, un marco político y una identidad propia. Por ello ha conocido toda clase de crisis, experimentado con revoluciones y contrarrevoluciones, se ha visto abocada a regímenes dictatoriales y de terror, ha sido utilizada como teatro de operaciones y experimentos de las superpotencias, para acoger en última instancia y generalizadamente a las incipientes democracias de final de siglo.

Si bien la democracia parece haberse instalado definitivamente en la totalidad de los países latinoamericanos con el beneplácito de todos, la injerencia continua de antiguos actores y la generalizada falta de alternativas políticas, nos hace pensar en un período actual de transición en el que aún está por ver la definitiva consolidación de los Estados democráticos. No hay que olvidar que en la última década, estos procesos de democratización se han visto alterados por las continuas apariciones de los tradicionales elementos desestabilizadores, si exceptuamos el ejército. 
A las dolorosas transiciones centroamericanas se han sumado el permanente estado de excepción en Colombia, el retorno del populismo en Venezuela y Argentina -en plena descomposición del Estado-, la vergüenza del final de la dictadura pinochetista en contraste con una modélica transición democrática en Chile, la irrupción indigenista en los frágiles procesos democráticos de Ecuador, Perú y Bolivia, así como la sempiterna injerencia de los militares oviedistas en el proceso de instauración democrática de Paraguay. Frente a estos elementos negativos merece la pena reseñar la renovación que recientemente se ha llevado a cabo en los gobiernos de México y Brasil, con la llegada al poder de sendas propuestas alternativas que marcan un hito constitucional, de la mano de la formación de gobierno del PAN -en sustitución del PRI tras setenta años- de Vicente Fox y del Partido de los Trabajadores de Inacio "Lula" da Silva, respectivamente.

Este continuo trasiego por el borde del precipicio en el que se han visto las sociedades latinoamericanas tiene mucho que ver con la gestación de los Estados y con los elementos ideológicos que los configuraron. La liberación de las ataduras coloniales no supuso una modificación sustancial de los mecanismos de acción de estas sociedades, que permanecieron regidas por las mismas pautas de conducta que les había implantado la metrópoli. Situación que permanecerá hasta finales de siglo, momento en el que la idea revolucionaria se expande por todo el continente tras la estela de la exitosa revolución mexicana. La semilla revolucionaria viene cargada de voluntad de crecimiento, de confianza en la educación, de la búsqueda de una participación política y social; de modernidad, a resumidas cuentas. Sus fuentes son múltiples, desde el liberalismo decimonónico a la oposición imperialista, pasando por una exaltación de los valores sociales indigenistas. La búsqueda de una identidad cultural, la lucha contra la dominación extranjera -ahora bajo un claro imperialismo económico-, el crecimiento del aparato del Estado, la llegada masiva de inmigrantes o la socialización de la política como fenómeno de masas, surgen como principales motivos de sublevación que lleva a la mayoría de los países hacia la formación de un nacionalismo beligerante que será asumido por todos los grupos hasta permear en la totalidad de los partidos políticos e incluso en otros agentes sociales como el ejército y la iglesia.

Hablamos del nacionalismo como del universo simbólico con el cual un conjunto de individuos se autoidentifica, hasta entregar su lealtad a una idea abstracta de nación. El nacionalismo refuerza la noción de Estado como fuente de autoridad y legitimidad, valorando al Estado-Nación como la for- 
ma ideal de organización política y a la nacionalidad como el origen de toda capacidad de creación cultural y de bienestar económico ${ }^{8}$. Sus efectos son asimismo diversos, abarcando manifestaciones militares violentas, agresividad diplomática, tendencias autárquicas y proteccionistas o dificultad a la hora de diseñar proyectos integracionistas.

El principal impulsor del nacionalismo fue el Estado liberal, a través del ejercicio de su autoridad en una época de formación de los Estados en la que no escaseaban las fuerzas centrífugas. Fue también fundamental en el mantenimiento de la independencia y de la integridad nacional mediante la defensa de sus fronteras.

Por otro lado, la intelectualidad procedente de las clases dirigentes tradicionales y de los sectores medios que aspiraban a engrosarla se movilizó ante el miedo de que las reivindicaciones políticas y sociales populares acabaran con su predominio social. La necesidad deneutralizar al incipiente movimiento obrero urbano sirvió de acicate para presentar una serie de propuestas nacionalistas que contaron con el apoyo de la iglesia y el ejército, tradicionales sectores aliados. La crisis de 1929 será un factor adicional al poner en evidencia las limitaciones del modelo exportador y de la dependencia económica. Ello llevará a reforzar la tendencia a favor del nacionalismo económico que, además del proteccionismo, llevaba aparejado el proyecto de construcción de un Estado nacional fuerte capaz de promover tanto el despegue industrial como el sentimiento antiimperialista. De esta manera, el nacionalismo se va convirtiendo en un fenómeno social capaz de movilizar a las masas de manera continua y permanente. Con el nacimiento y desarrollo de las clases medias y populares urbanas, su progresiva participación, su concienciación social y política, la difusión de la enseñanza, la ampliación del sufragio y la ayuda de la prensa, se irá allanando el camino de los regímenes populistas, que tienen en el nacionalismo uno de sus ingredientes fundamentales.

El populismo será el movimiento político que mejor rentabilizará el nacionalismo inherente a los Estados de América Latina. Considerado desde un punto de vista sociológico, el populismo es una reacción nacional a la modernización del Estado realizada desde el exterior. Su función es mantener y recrear una identidad colectiva a través de una serie de transformaciones económicas aceptadas. Es una tentativa clara de control antielitista del cambio social.

8 A. Touraine, (1989), pp. 168-169. 
Se dirige directamente al pueblo mientras elimina las formas de representación política habituales en occidente. Pero el pueblo nunca se organiza espontáneamente por sí mismo. Por tanto serán los intelectuales y las clases medias las que obtengan el papel más importante, que utilizarán para la formación definitiva de una conciencia nacional.

El populismo otorga el papel primordial al Estado, única expresión del pueblo y de la historia nacional. Contrariamente a lo regulado en las democracias occidentales, con regímenes representativos que organizan y controlan al Estado, en los Estados populistas es el Estado el que controla al sistema político. Este ejercicio de control lo extiende a todo el espectro social, negando la oposición y el conflicto social. De esta manera la sociedad civil se ve abocada al silencio, a la no participación si no es a requerimiento del Estado. El populismo identifica la sociedad con el Estado. El Estado domina a la sociedad ${ }^{9}$.

Alain Touraine denomina al Estado resultante de este modelo populista como Estado Nacional-Popular, hegemónico para la casi totalidad de América Latina como resultante del modelo latinoamericano de desarrollo. El Estado posee un papel central en las sociedades latinoamericanas, sin el cual, éstas se verían abocadas a la disolución en los particularismos y la violencia. Tal es su desvertebración. La sociedad no tiene más que una autonomía, una organización y una capacidad de acción limitada, siendo muy difícil pasar de los obreros a la clase obrera, o de los campesinos al movimiento campesino. El nacionalismo se apoya sobre todas las categorías sociales, cuyas luchas se asocian a la defensa nacional, dado que el poder económico se encuentra en manos extranjeras.

El sistema nacional-popular mezcla Estado, instituciones y fuerzas sociales. La aparición de cualquier movimiento social constituido al margen del Estado provoca la crisis de este sistema, a partir de la cual aparecen los movimientos de liberación nacional. De esta manera, la llegada de las dictaduras militares impuso la idea de una cesura en la historia de América Latina, tratando de interrumpir la memoria colectiva. La violencia política, de la mano de las dictaduras militares, de los grupos paramilitares o de la guerrilla revolucionaria, aparece como oposición a los regímenes nacionales-populares en los que se manifiestan las divergencias entre crecimiento económico y demandas sociales debido a la crisis financiera y económica.

9 A. Touraine, (1989), p. 163. 
Pero es un síntoma más de nacionalismo, ya que la lucha contra el Estado se debe a la consideración de éste como representante de los intereses extranjeros, sempiternos dueños de las economías dependientes latinoamericanas. Los medios dirigentes y oligárquicos se deshacen de este Estado para rechazar las demandas populistas o revolucionarias, atraídos por una nueva incorporación a los mercados internacionales y por explotar las ventajas comparativas como propietarios de actividades exportadoras.

La irrupción violenta de las dictaduras militares en buena parte de los Estados latinoamericanos se fundamenta en dos factores fundamentales. El principal será la intervención y apoyo prestado por Estados Unidos, que en plena guerra fría se siente temeroso de las tendencias filocomunistas de los diferentes movimientos populares. El otro factor será la debilidad de las sociedades civiles, incapaces de coordinar una respuesta contundente debido a las carencias que aquí venimos argumentando.

El carácter represivo fue el responsable del mantenimiento de la unidad social en estos períodos dictatoriales, cuya verdadera situación era de fragmentación y descomposición social. Sólo una nueva y pavorosa crisis financiera y económica surgida alrededor de la deuda externa al inicio de la década de los ochenta será capaz de acabar-por derribo-con los regímenes militares.

La vuelta a la democracia aparece como la solución de todos los problemas. Esta visión triunfalista pone de manifiesto la verdadera novedad que el significado de democracia adquiere en América Latina. Este concepto es verdaderamente una idea nueva, escasamente desarrollada en el continente, que continuamente había perdido la batalla comparativa frente a las propuestas revolucionarias, y que incluso se había relacionado con el conservadurismo liberal oligárquico. No obstante, la restauración de los gobiernos democráticos no ha sido posible sin que se restablezcan ciertas continuidades entre los regímenes nacional-populares y los democráticos. Así pues, la democracia se vio abocada a solucionar dos de los tres problemas fundamentales: la finalización de los regímenes dictatoriales y la respuesta del sistema político a las demandas sociales. El otro problema fundamental, el económico-financiero de la deuda externa, será el principal escollo que tendrán que salvar.

La extensión de la democracia por todo el continente se irá generalizando a partir de ese momento, si bien no será fácil el camino a recorrer. A las dificultades económicas hay que añadir el enconamiento de algunos sectores 
reacios y la injusta tibieza a la hora de cerrar las viejas heridas abiertas por la violencia de los militares. Las instituciones no están asentadas, y son raros los países en los que los Parlamentos han conseguido un papel central capaz de imponer programas a largo plazo. Para algunos, el mantenimiento de un sistema presidencialista -que demuestra una vez más la cercanía de las sociedades latinoamericanas con los Estados Unidos- pleno de poder, es una rémora clara para el fortalecimiento de los actuales procesos democráticos. Igualmente se echan en falta otras reformas constitucionales cuyos objetivos deben ser el reforzamiento de los regímenes democráticos. La vuelta de la democracia no ha significado, en ningún caso, una mayor integración social y política que promueva el tan necesitado consenso sobre los principios de organización económica y social. Las sociedades latinoamericanas siguen estando dominadas por la dualización, acentuada últimamente por el crecimiento del paro, del subempleo y todas las formas de marginalidad y de desorganización social.

No sería, sin embargo, de justicia dejar de hacer mención a los efectos positivos que la década de los noventa ha traído consigo a pesar de las continuas crisis. Así, habría que mencionar la transición a la estabilidad política como un hecho fundamental y esperanzador; la recuperación económica de algunos países en términos macroeconómicos; y, sobre todo, la emergencia de nuevos agentes sociales que pueden aportar en el futuro nuevos mecanismos de acción que consoliden la tendencia a la modernización y el desarrollo.

Aun así, la crisis institucional permanente que viven la mayoría de los Estados latinoamericanos se convierte en un factor clave que aporta grandes dosis de inseguridad, inestabilidad y desconfianza en el seno de las sociedades civiles. Resulta extremadamente difícil llevar a cabo cualquier tipo de política cuando las principales instituciones de los países se encuentran en la picota, cuestionadas por la mayor parte de una sociedad que, a pesar de su evidente debilidad, reclama cambios de rumbo y aires nuevos que raramente se llevan a cabo.

\subsection{Las deficiencias del modelo social}

La interminable crisis económico-financiera y los programas de ajuste estructural impuestos por la comunidad internacional a cambio de seguir alimentando los mecanismos de financiación han causado estragos sobre el edificio social de los Estados de América Latina. Estas medidas se han cen- 
trado en la estabilización económica y en el ajuste estructural. La primera de ellas contempla una fuerte reducción del crédito doméstico, la devaluación de los tipos de cambio y la liberalización de los precios internos. El ajuste estructural conlleva la integración en los mercados mundiales, la desregulación de las actividades económicas y la redefinición del papel del Estado. La obligación del equilibrio presupuestario, la privatización de empresas y servicios públicos y la restricción del crédito ha perjudicado claramente a los sistemas de redistribución social, que se han visto muy mermados en los sectores principales: educación, sanidad, prestaciones por desempleo y seguridad. Todo ello configura un panorama de alta inestabilidad social. Llueve sobre mojado si tenemos en cuenta la ya de por sí situación deficitaria que los niveles de desarrollo alcanzan en el continente.

Una visión de conjunto nos la ofrece el Panorama Social de América Latina 2002-2003, realizado por la CEPAL. El informe se divide en cinco capítulos: magnitud y evolución de la pobreza, el hambre, las desigualdades de género, un análisis sobre la evolución del gasto social y un análisis sobre la situación laboral y las políticas de empleo.

El capítulo sobre pobreza y distribución del ingreso ofrece como resultado el estancamiento en el proceso de superación de la pobreza. En el período 1999-2002 tan sólo se registró un descenso del 0,4\%, quedando para esa fecha situada en un $43,4 \%$ de población afectada por esta lacra. La pobreza extrema creció un $0,3 \%$, situando la tasa en un $18,8 \%$ de la población total. El escaso crecimiento hasta el año 2000 y el posterior decrecimiento económico son los responsables de estas cifras tan desalentadoras. El deterioro se ha hecho más palpable en países como Argentina y Uruguay, que partían de mejores cifras. Haití, Nicaragua y Bolivia son los países más afectados por la pobreza y la indigencia.

El hambre y la inseguridad alimentaria son fenómenos relacionados con la pobreza extrema, pero no se confunden con ella. A finales de los noventa, la subnutrición afectaba a un $20 \%$ de la población de países como Bolivia, Nicaragua, Honduras, Guatemala, Haití o la República Dominicana, mientras que no llegaba al 5\% en países como Chile, Argentina o Uruguay. La desnutrición se redujo en la mayoría de los países, si bien el parón en el crecimiento frenó esa reducción. La población infantil es la más afectada.

En cuanto a la pobreza y desigualdad desde la perspectiva de género se han registrado logros notables, mostrando una población femenina más educada, especialmente en los tramos superiores. No obstante, el capital 
humano femenino sigue estando subutilizado y es objeto de múltiples discriminaciones. Durante los años noventa, la tasa de actividad económica de las mujeres creció a un mayor ritmo que la masculina. Sin embargo, enfrentan mayores dificultades para ingresar en el mercado laboral. La ocupación se ha mantenido casi sin modificaciones, con un leve descenso entre las ocupadas en el servicio doméstico y los servicios personales, y un ligero aumento en la agricultura y el comercio. Los ingresos que percibían las mujeres en el mercado de trabajo eran aproximadamente el $75 \%$ de los ingresos masculinos y la brecha se ha acentuado entre las mujeres de mayor educación. En gran parte de los países, las mujeres jóvenes con más de diez años de estudio son una mayoría entre los desocupados, superando también a los hombres. La mayor educación de las mujeres, especialmente las que poseen educación superior, no tiene el mismo retorno que para los hombres, es decir, no se traduce ni en igualdad de empleo, ni de ingresos para los mismos años invertidos en educación.

El gasto social ha mostrado en el período una tendencia positiva, pero ésta se ha visto frenada por la desaceleración económica de la región. La década de los noventa se caracterizó por un importante aumento de los recursos destinados a los sectores sociales (educación, salud, seguridad y asistencia social, vivienda y servicios básicos). Este aumento fue generalizado, sólo los países centroamericanos y Venezuela no lograron una expansión significativa. Sin embargo, al aumento del gasto social no se vio acompañado de una reducción de las pronunciadas disparidades entre países. Y ello pese al importante esfuerzo de estos por elevar la fracción del PIB destinada a los sectores sociales, a fin de compensar en parte la reducción de los ingresos fiscales vinculada al menor dinamismo de la expansión. La relación entre el gasto social y el PIB aumentó sólo en un 1,7\% de 1996 al 2001, situándolo en un 13,8\% (en algunos países no llega ni siquiera al 10\%).

La desaceleración de la economía y la contracción del PIB en términos absolutos observada en varios países frenó la expansión del gasto social a partir de 1998. Otro dato a tener en cuenta es la tendencia a la reducción del ritmo de expansión del gasto social durante el último quinquenio, aunque oculta diferencias importantes entre países. Cabe destacar el esfuerzo en el mantenimiento del gasto social en capital humano, educación y salud.

Estos datos muestran su verdadero perfil cuando se extrapolan con las estadísticas de las zonas más desarrolladas. El siguiente cuadro refleja la enorme diferencia porcentual en términos medios con la Unión Europea. 
GRÁFICO 1

Gasto Social sobre PIB en América Latina y la Unión Europea

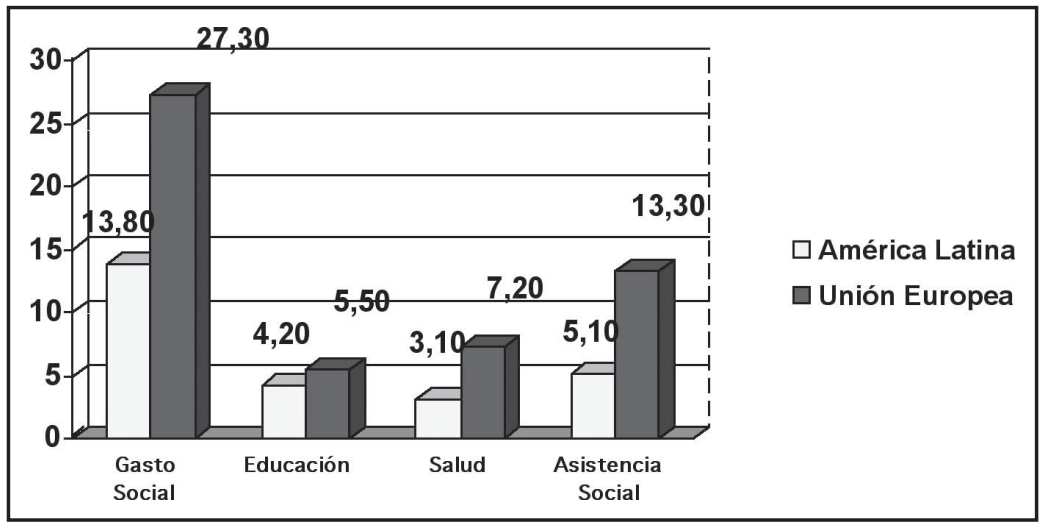

Fuente: CEPAL (2003). Panorama Social de América Latina. En \%.

La evolución de la agenda social, centrada en la situación laboral y las políticas de empleo ha recogido en el último sexenio un proceso de modificación de las legislaciones laborales de carácter continuador, aunque a un ritmo menor. Se han ratificado los convenios internacionales fundamentales sobre la no discriminación en el empleo y la mayoría también ha suscrito los relacionados con el trabajo forzoso y la libertad sindical.

No ha sucedido lo mismo con el trabajo infantil. Varios países aún no han suscrito los convenios de la Organización Internacional del Trabajo. La normativa sobre la edad mínima para trabajar vigente en la región presenta contradicciones con la internacional y una gran diversidad entre los países y dentro de ellos. Los mayores descensos del índice medio de salarios durante el mismo período se registraron en Ecuador y Uruguay, debido a las crisis recientes que redujeron el crecimiento económico. También en México, el salario mínimo real acusó una importante disminución.

La tasa de sindicalización es extremadamente baja y el marco regulador que define las políticas laborales muestra una gran diversidad de criterios en lo referente a la edad mínima para trabajar, las formas de contratación y los derechos de sindicalización y huelga. Esto pese a los avances legislativos mencionados, persistiendo serios problemas en el cumplimiento de la nor- 
mativa existente. Como muestra, destaca el hecho de que, en toda la región, solamente seis países cuentan con seguro de desempleo: Argentina, Brasil, Chile, Ecuador, Uruguay y Venezuela. Estos seguros son de tipo contributivo, con financiación mixta aportada por los trabajadores, los empresarios y el Estado, si bien los porcentajes del salario que pagan los trabajadores y las contribuciones de los empresarios, así como los criterios de elegibilidad para recibir la indemnización, también difieren según los países, lo que hace difícil su evaluación. Dado su carácter contributivo, su cobertura se limita principalmente a los trabajadores formales, es decir, a los que cuentan con un contrato y con cierta continuidad en su puesto. Se da la circunstancia de que, en varios países las indemnizaciones por despido representan una mejor compensación financiera que los seguros, ya que, cuando existen, ni siquiera son compatibles.

El análisis aquí expuesto resume un panorama social bastante desalentador, cuyo rasgo más negativo no estriba en la descripción de la situación actual, sino en la evolución seguida desde el inicio del desarrollo. Muestra una indudable dificultad para el despegue definitivo hacia situaciones de desarrollo. Los países más atrasados se mantienen estancados en niveles de pobreza, desnutrición, educación, salud y servicios sociales cercanos al tercer mundo. Mientras, los más avanzados han seguido un proceso recesivo que no les ha permitido alcanzar el despegue definitivo hacia el desarrollo.

Algunos de los aspectos del panorama social nos ayuda a comprender mejor la situación en la que se hayan buena parte de estas sociedades y las dificultades que tienen para constituirse como una sociedad civil participativa, vertebrada e integrada en los procesos económicos y políticos de sus respectivos países.

\section{Escepticismo y desencanto social. Incidencia sobre la Integración regional}

\subsection{Unos antecedentes marcados por la frustración}

Como ya se apunta en la introducción, históricamente la integración latinoamericana no es una novedad. Sus inicios se podrían remontar incluso a la idea que Simón Bolívar preconizó, tras la independencia, en torno a la defensa y consolidación de la libertad y la independencia de los nuevos Estados. Pero habría de pasar un siglo para que fructificasen formalmente 
los primeros intentos integracionistas.

El nacimiento oficial de la CEPAL como órgano dependiente de las Naciones Unidas, en 1951, será un hito fundamental. Este organismo elabora -de la mano del economista argentino Raúl Prebich- una propuesta económica para América Latina que se desmarca de la tradicional apuesta neoliberal. De base estructuralista, adopta nuevas líneas de actuación en el comercio exterior, se decanta por la integración regional, por la planificación y por la intervención del Estado, en busca de un desarrollo que actúe sobre la dimensión social de cada uno de los países.

Con este fundamento teórico, y aupados por el crecimiento industrial de la época, comienzan a proliferar en la década de los cincuenta diversos procesos de integración regional que agruparán a la casi totalidad de los países latinoamerianos y caribeños. Desde 1960, de norte a sur van apareciendo el Mercado Común Centro Americano (MCCA), la Asociación Latino-Americana de Libre Comercio (ALALC), transformada posteriormente en la Asociación Latino-Americana de Integración (ALADI), el Grupo Andino (GRAN) y algo más tarde la Comunidad y Mercado Común del Caribe (CARICOM). Lógicamente, cada proceso integrador dibujó una trayectoria diferenciada plagada de luces y sombras, con unos períodos iniciales que se caracterizaron por la consecución de los objetivos prefijados. Con esta primera fase, llena de optimismo, contrasta una segunda fase de estancamiento en la que se comienzan a cuestionar los modelos para posteriormente, ya en la década de los ochenta, iniciar un giro involucionista que les llevará a su paralización práctica.

A pesar de los esfuerzos y las energías invertidas, estos procesos de integración regional latinoamericana no consiguieron los resultados esperados. Su acción apenas sirvió para dar los primeros pasos en la creación de zonas de libre comercio. El comercio intrarregional nunca alcanzó el umbral del $20 \%$ del comercio total de la región ${ }^{10}$-salvo el caso centroamericano en el año 1994 con un 24,5\%-, siendo especialmente limitado en el cono sur y en el Grupo Andino. Esta cifra resalta aún más si la comparamos con las cuotas comerciales intrarregionales de los países pertenecientes a la Unión Europea para el mismo período, que gira en torno al $60 \%$. La integración falló porque la economía y la política también fallaron. El fracaso fue sistémico.

Siguiendo a Raúl Grien, podemos acordar que los primeros movimientos

10 F. Batalla, Síntesis, no 24 (Julio-Diciembre 95). 
integradores latinoamericanos resultaron un claro fracaso, salvo logros muy puntuales focalizados casi en su mayoría en la región centroamericana ${ }^{11}$. Este autor repasa, mediante un análisis exhaustivo, las causas de este fracaso desde un punto de vista economicista ${ }^{12}$, pero pasa de largo sobre los aspectos sociales. Así, centra dicho análisis en cuatro aspectos: causas estructurales, causas instrumentales, causas exógenas y defectos de ejecución.

Entre las causas estructurales señala la desigual dotación de factores; la reducidas dimensiones de los mercados; la carencia de complementariedad productiva; una distribución cuantitativa de las transacciones recíprocas intrarregionales muy dependientes del tamaño económico de cada país; una profundización en la brecha que separa al país de mayor desarrollo con el de menos; una mala política de reciprocidad y armonización; un irregular cuadro monetario; una configuración arancelaria errática y una reducida capacidad de ahorro interno.

Como causas instrumentales destaca las numerosas normativas que se elaboraron para hacer eficaces los modelos que ni siguiera llegaron a ejecutarse. En otros casos, algunos instrumentos fueron retirados antes de su aplicación, y otros muchos fueron incumplidos. La preponderancia comercialista al margen del desarrollo, la inoperancia de los instrumentos, el entrabamiento de los propios mercado que impuso la normativa de negociación producto a producto, la incoherencia de muchas resoluciones, la ambigüedad e inaplicabilidad de las normas y la falta de concordancia entre ellas, supuso la obtención de los efectos contrarios que se pretendieron. Todo ello se acumulará en 1982, demostrando la incapacidad para hacer frente a la crisis.

En este fracaso también tuvo mucho que ver la coyuntura internacional. Siempre mencionando única y exclusivamente los aspectos económicos subraya, entre otros, el proteccionismo de los mercados exteriores, que redujo las exportaciones latinoamericanas; las políticas de ajuste con la consiguiente limitación de importaciones; la falta de liquidez que acentuó la contracción del comercio recíproco intrazonal; el deterioro de los términos de intercambio, originado por las situaciones recesivas de las economías occidentales, el endeudamiento externo y las tasas de interés, que forzó a realizar transferencias de recursos al exterior; la norteamericanización del

11 P. Caldentey, (2001), pp. 438-439.

12 R. GRIEN, (1994), pp. 368-385. 
comercio exterior del subcontinente, debido a la actitud del resto de los mercados mundiales; y las nuevas tecnologías, que transformaron la producción, distanciando la brecha competitiva de los productos de América Latina y minando así sus ventajas comparativas.

Finalmente, Grien pasa de puntillas por otro factor que a nuestro entender es el más importante de todos: la escasa puesta en práctica de los instrumentos por parte de los organismos e instituciones comunitarias, así como de los gobiernos. Y es en este punto donde retomamos el hilo argumental del presente trabajo. Estos procesos, si bien contaron con el respaldo de los gobernantes, se llevaron a cabo de espaldas a las sociedades respectivas de cada país. El desconocimiento y la desinformación generalizada no permitieron que estas sociedades, ya de por sí escasamente estructuradas y con graves problemas de pervivencia, participaran de los mecanismos de puesta en marcha de dichos procesos. Se cometió un claro error de apreciación al sobrevalorar la capacidad y el poder de los Estados y de los gobernantes en momentos en los que las convulsiones políticas tendían a despejar constantemente la mesa de juego. La inexistencia de participación por parte de los actores sociales no permitió consolidar una estructura normativa que aguantara los envites de la ingobernabilidad y de las crisis económicas. Las decisiones nunca se transformaron en hechos, nunca pasaron del postulado político a la realidad.

Tras los desastres económicos - a los que se añadieron terriblemente otros de carácter natural- de la década perdida, encontramos en la actualidad de América Latina un panorama similar al producido en la década de los cincuenta en lo que a los procesos de integración regional se refiere. Aunque ahora surge de un posicionamiento defensivo surgido de una crisis brutal, también tendrá en las modificaciones conceptuales de la CEPAL un asidero teórico. La redefinición cepalina girará ahora en torno al "regionalismo abierto", concepto este de bajo perfil en el que se favorece el proteccionismo y la intervención estatal, pero con la novedad de incluir propuestas y medidas de ajuste similares a las neoliberales, aunque aplicadas con heterodoxia. Así, como ya lo fueron los cincuenta, los años noventa se van a caracterizar por la profusión de acuerdos comerciales y de integración. El resurgimiento aparece ahora con más vigor, avalado por los beneficios que la integración europea ha dejado en países tan cercanos como España y Portugal. Aparecen el Pacto Andino, el MERCOSUR, se dan nuevos bríos al CARICOM y renace de sus cenizas la integración centroamericana de la mano de la SICA (Sistema de Integración Centro-Americano) que viene a sustituir al fenecido-aunque no 
enterrado-Mercado Común Centro-Americano. Incluso México se adhiere al Tratado de Libre Comercio Norteamericano (NAFTA), junto a Estados Unidos y Canadá. La totalidad de los países latinoamericanos participan en algún proceso de integración subregional, y algunos de ellos en varios a la vez ${ }^{13}$.

En esta reinvención integracionista se vuelven a manifestar los mismos fantasmas del pasado, si bien destacan aspectos que ahora han mutado proporcionando nuevos paisajes y horizontes. El escenario político se ha modificado positivamente debido a la generalización de las democracias que, aunque se encuentran en vías de consolidación, pasan por ser la alternativa política definitiva, sobre todo tras el derrumbamiento de la URSS. Persiste la inestabilidad política y se agudizan los problemas sociales, como la dualización imparable y la aparición de nuevos elementos de discordia social como el movimiento indigenista. Igualmente no termina de definirse qué modelo de desarrollo resulta el escogido, si el de las políticas de ajuste estructural o el de las neoestructuralistas; mientras tanto, la propuesta estadounidense de su Área de Libre Comercio para las Américas (ALCA) ha venido, si cabe, a complicar mucho más el panorama, debido a la posición de muchas regiones con altos niveles de dependencia comercial con respecto al gigante norteamericano. A nivel económico, siguen estando presentes las mismas deficiencias que nos aportaba Grien para los procesos de décadas pasadas. Se mantiene también una notable ignorancia por parte de los principales actores sociales, con la particularidad de que en la actualidad se ha modificado en cierto modo el panorama social con el nacimiento de un incipiente movimiento en el seno de la sociedad civil, propiciado en gran parte por los avances tecnológicos en telecomunicaciones y por la concienciación ciudadana ante los efectos de la globalización económica. Finalmente, a nivel político, se manifiesta una clara falta de interés y liderazgo, si bien últimamente se están recibiendo buenas noticias en torno a la actuación del recientemente elegido presidente de Brasil, Lula da Silva, figura que aúna todos los requisitos necesarios para ejercer dicho liderazgo.

\subsection{El recelo de la sociedad civil ante los acuerdos regionales de integración}

Pese a la debilidad que, según vimos en el apartado dos, el concepto de sociedad civil adquiere en América Latina, no cabe duda que nos encontramos en un momento crucial de su desarrollo, propulsado por los avances del

13 J. J. Romero. Prólogo en P. CAldentey, (2001), pp. VII-XII. 
proceso democratizador y por las últimas novedades tecnológicas. Al mismo tiempo, los diferentes organismos surgidos de otros tantos acuerdos de integración se han manifestado oficialmente a favor de un mayor protagonismo de la sociedad civil en dichos procesos, conscientes de la importancia que deriva de su participación. En los últimos tiempos se ha venido configurando un importante movimiento de este tipo de grupos por toda América Latina, fomentando los foros de participación y el intercambio de información, así como el contraste de objetivos y la unificación de criterios reivindicativos.

Sin embargo, estos movimientos-y el resto de la sociedad en general-siguen mirando con escepticismo, recelo y a distancia los procesos de integración regional. Cabría preguntarse entonces cuáles son los motivos que sugieren este escepticismo social; o más concretamente: ¿por qué la sociedad civil latinoamericana contempla con tanto recelo los procesos de Integración regional?. Varios son los factores que confluyen para que esto sea así; particularmente destacaría cuatro.

El primer factor sería la propia configuración social de la mayoría de los países. Estas sociedades carecen de estructura y vertebración, manteniéndose cautivas de graves desequilibrios y marginalidades. Su debilidad sólo les permite una autonomía, una organización y una capacidad de acción limitada. Por todo ello, su participación es siempre muy escasa. No existe una relación de representatividad entre los diversos grupos sociales, sino más bien la mezcla entre diversos órdenes representativos cuyos resultados provocan una desarticulación social que destruye cualquier tipo de correspondencia entre ellos.

Falta cohesión social, no existe un diálogo permanente entre los diversos sectores de la sociedad civil. El modelo de desarrollo latinoamericano ha creado una sociedad muy compleja y heterogénea donde difícilmente se aprecia la separación entre la sociedad civil y el Estado, y en la que ésta no se siente vinculada a ninguna otra movilización que no sea la solicitada por aquél. Los actores sociales sólo responden a las iniciativas del Estado, que los utiliza constantemente como instrumento del Estado nacional-popular. Así, normalmente es el Estado el que ocupa su lugar como dinamizador social, como actor político, cultural, social y económico.

Su condición de sociedad dependiente hace que no le resulte fácil expresarse en libertad. Al mismo tiempo, la falta de madurez -debido a unos bajos índices de formación- dificulta notablemente su inserción y su complicidad en temas de sensibilización social, como pueden ser la globalización, el 
desarrollo o la consolidación del Estado democrático.

El segundo motivo que causa el escepticismo en el seno de la sociedad civil podríamos denominarlo como desencanto social. Esta frustración sobreviene debido al continuo desprestigio de la gestión política, económica o de justicia, y de la desconfianza que la mayoría de la sociedad profesa hacia las elites administrativas. No debemos olvidar que los procesos de integración regional de las décadas anteriores constituyeron un rotundo fracaso, y que no se percibe por parte de la sociedad civil un escenario que difiera excesivamente de aquellos otros. Los protagonistas siguen siendo los mismos: una clase política sin credibilidad y unos modelos de desarrollo económico y social que han demostrado fehacientemente su ineficacia. La sociedad puede entender que sin desarrollo social no habrá desarrollo económico, ambos deben avanzar al unísono. Para ello, la aplicación de políticas neoliberales no parece la mejor de las fórmulas, ya que no ha resuelto los principales problemas económicos y sociales.

Hasta ahora, la sociedad civil se ha visto marginada de toda intervención en los procesos de integración regional. El protagonismo ha recaído siempre en la clase política, y en especial en la gobernante. Las reiteradas declaraciones de intenciones de los dirigentes regionales en las sucesivas cumbres gubernamentales no calan en la opinión pública debido al deterioro de la credibilidad de los protagonistas políticos.

Los defectos de diseño de algunos procesos ha creado mayor confusión y desconfianza en ciertos sectores de la sociedad: desorden jurídico, profusión de instituciones, complejidad del sistema o desequilibrio de poderes.

Otros aspectos internos del pasado se mantienen vivos en la memoria colectiva de las diversas sociedades civiles, como el rechazo a la cesión de soberanía. El peso del nacionalismo nunca permitió la supranacionalidad ni estuvo dispuesto a ceder cuota alguna de poder, al tiempo que las políticas proteccionistas se contradecían con las políticas de integración.

Un tercer factor de importancia se situaría en la necesidad de profundización en los procesos democráticos que permita una gobernabilidad sin sobresaltos de carácter perdurable. La sociedad civil podría considerar que un elemento clave de recuperación de la confianza social sería la renovación del Estado. Este debería poseer los atributos de los que disfrutan las modernas democracias occidentales, promoviendo transformaciones esenciales como la reforma fiscal, la descentralización, la despolitización, la claridad y el compromiso social. El Estado debe ser concebido como pilar del desa- 
rrollo. Una sociedad civil organizada entiende que en América Latina existen temas que adquieren mayor relevancia en su resolución que la integración regional, si bien éste es un factor que beneficiaría enormemente la consecución de logros complementarios de desarrollo. A su vez, una apuesta por la calidad democrática y la persecución de mayores cuotas de bienestar social, repercutiría en mayores parámetros de identificación y participación en los procesos integradores.

La inestabilidad política permanente, el incumplimiento, casi sistemático, de los acuerdos firmados por parte de los gobiernos y la incapacidad de institucionalización de una sociedad durante casi dos siglos -en algunos países-, está generando una conciencia colectiva pesimista muy negativa que tiende a pensar que el desarrollo es estructuralmente inviable. Si esto es grave, aún más peligrosos pueden ser sus efectos desintegradores en unas sociedades con altas dosis de dualización.

Por otro lado, son frecuentes las críticas contra acuerdos comerciales y organizaciones internacionales por su falta de apertura a los ciudadanos. Según una opinión del propio Guillermo Fernández de Soto siendo Secretario General de la Comunidad Andina: "Suelen ser vistos como reuniones de burócratas, con poca comunicación hacia los particulares. En la CAN trabajamos para construir acuerdos cada vez más abiertos y transparentes, pero aún queda mucho por andar, informar más a los ciudadanos acerca del proceso de integración..."14. En la cumbre de Quito, el CAN presentó el documento "Nuevo diseño estratégico", que señala tres líneas de acción para profundizar en el proceso de integración andina. Las tres hacen mención al débil calado social y a la necesidad de incidir en los procesos de democratización para llegar a la población (1 $1^{a}$, profundización democrática del proceso; $2^{a}$, proyección externa; y $3^{\mathrm{a}}$, agenda social) ${ }^{15}$.

Por último, encontraríamos un cuarto motivo de recelo en las continuas campañas de desprestigio que diversos grupos de poder, relacionados con los tradicionales sectores exportadores, lanzan constantemente a través de los medios de comunicación a los que tienen acceso. Se quiera o no, en una época como la actual, en la que los medios de comunicación se han erigido en los verdaderos interlocutores válidos de las sociedades, este tipo de mensajes va calando, sobre todo en los sectores informales urbanos, cuya

14 CAN www.comunidadandina.org (5/11/03).

15 CAN www.comunidadandina.org (5/11/03). 
participación en los beneficios sociales se conjuga con dificultad, y que tanto abundan en América Latina.

Javier González Fraga ${ }^{16}$, economista jefe de la UIA reclama una revisión del MERCOSUR. Prefiere que se transforme en un área de libre comercio, acotando su alcance. Para este dirigente empresarial, los acuerdos con Brasil perjudican la exportación de productos industriales argentinos. El documento de la UIA, publicado por el diario Clarín el pasado catorce de noviembre, está en sintonía con las críticas a la relación comercial con Brasil que marcaron las reuniones de trabajo del Grupo de Industriales Argentinos en Rosario. Para el Sr. González Fraga, en declaraciones a dicho diario: "son varios los sectores que están al límite de su capacidad de producción, y la demanda que no pueden cubrir está siendo cubiertas con importaciones brasileñas”. Siguiendo en Argentina, nos serviría también para ilustrar este apartado la encuesta llevada cabo por el mismo diario Clarín entre sus lectores digitales y los empresarios presentes con ocasión del Coloquio organizado por el Instituto de Empresarios Argentinos celebrado en Mar del Plata. En dicha encuesta, realizada sobre diversas preguntas relativas al MERCOSUR, cabe destacar la que indicaba que los lectores del diario votaron mayoritariamente a favor de la moneda común latinoamericana y a la incorporación de Cuba al MERCOSUR. Por el contrario, los empresarios rechazaban mayoritariamente la propuesta de la moneda común, mientras que prevalecía la división de opiniones con respeto la incorporación de Cuba a los mercados integrados ${ }^{17}$. Otra muestra más nos la ofrece Daniel Novegill, vicepresidente ejecutivo del grupo siderúrgico Techint, para el que "La siderurgia prefiere a Estados Unidos antes que al MERCOSUR; yo no tengo los números, pero me parece que el balance neto del MERCOSUR no es favorable del todo para Argentina. Prefiero un acuerdo bilateral en torno al ALCA. El Mercosur no se negoció bien, habría que replantearlo"18. El señor Novegill será desde el uno de enero de 2004 el titular del Instituto Latinoamericano del Fierro y del Acero (ILAFA).

Para Sebastián Edwards, economista chileno de la Universidad de California, "el MERCOSUR fue una mala idea". Este economista reivindica las políticas del Consenso de Washington de 1989 y critica el reciente Consenso

16 J. GonZÁlez FraGA, www.clarin.com/arg (14/11/03).

17 Diario Clarín, www.clarin.com/arg (12/11/03).

18 D. NovegiLL, www.clarin.com/arg (7/11/03). 
de Buenos Aires: "no tiene seriedad académica no es más que una colección de buenas intenciones" 19 .

En la editorial del diario ecuatoriano El Comercio del día 27 de Octubre de 2003, podíamos leer cómo "los grupos de interés económico han sido reacios a posiciones estratégicas comunes en escenarios internacionales como la CAN, debido a la controversia entre Guayaquil y Manta. Con estos enfrentamientos, la inserción del país en el mercado mundial será imposible"20.

Estas ilustraciones reflejan a las claras el estado actual de las cosas. En buena parte de los países existen grupos de poder económico claramente contrarios a los procesos de integración regional. Sus intereses siguen respondiendo a posiciones tradicionales y sus manifestaciones públicas están dirigidas certeramente para mediatizar a la opinión pública.

3.3. Los nuevos escenarios de debate y participación de la sociedad civil en los procesos de integración regional. Cumbres, foros y medios de comunicación

Como hemos venido reiterando, los procesos de democratización creciente y los continuos llamamientos por parte de los dirigentes, unidos a las innovaciones en el campo de las telecomunicaciones, han traído consigo una riada de asociacionismo en el seno de la sociedad civil de buena parte de América Latina. Los procesos de integración regional se han visto muy enriquecidos gracias a esta nueva aportación, generando en torno suyo un debate permanente que podría cambiar la trayectoria que venían recorriendo hasta ahora.

Las principales manifestaciones o ámbitos de participación se centran en torno a las Cumbres de Jefes de Estado, a los Foros de debate y a la muy numerosa presencia de asociaciones de la sociedad civil y ONGs mediante páginas webs insertadas en internet.

Las Cumbres de Jefes de Estado suelen promover en torno suyo concentraciones y manifestaciones reivindicativas que llevan consigo la creación de grupos de debate procedentes de diversas representaciones del asociacionismo civil, cuyas conclusiones pretenden ser recogidas, analizadas y tenidas en cuenta por los organismos integradores. El proceso de Cumbres

19 S. EDWARDS, www.eleconomico.cl (19/10/03).

20 Editorial, www.elcomercio.com (27/10/03). 
le ha proporcionado un importante estímulo a la participación de la sociedad civil desde la aprobación por parte de la Organización de Estados Americanos de su documento "Directrices para la participación de las organizaciones de la sociedad civil en las actividades de la OEA". En las negociaciones sociales del proceso de Cumbres, la participación es amplia, reconocida y aceptada por los gobiernos, lo que no sucede tanto en las negociaciones comerciales, lideradas por los ministros, y donde la participación de la sociedad civil está limitada. En las Cumbres de las Américas ${ }^{21}$ también se vienen realizando declaraciones de buenas intenciones sobre la participación de la sociedad civil, aunque ello no se está viendo refrendado en sus políticas. No obstante, hay que insistir en que sí se está logrando la progresiva participación y valoración.

Otro ámbito de participación se sitúa en torno los Foros de debate. Estos suelen reunir a una serie de especialistas en torno a un tema de debate, sobre el que se discute y se extraen conclusiones que posteriormente se vuelcan sobre un documento de conclusiones que servirá de referente argumental a partir de ese momento. Suelen ser bastante fructíferos, y sus proposiciones se encuentran en la vanguardia de los debates institucionales. Los contenidos generales de las ponencias y las conclusiones extraídas dan una idea de la amplitud y de la profundidad con que se tratan todos los temas.

Entre los más recientes destacan el Tercer Foro temático regional integración con equidad, celebrado en Angra dos Reis, Brasil. Sus ponentes trataron la práctica totalidad de problemáticas que surgen en torno a los procesos de integración regional. A modo de ejemplo ilustrativo del alto nivel que alcanzan estos foros y de la completa temática que abordan, podría destacar muy resumidamente algunas de las exposiciones de este foro brasileño.

Roberto Rubio ${ }^{22}$ centró su exposición en los elementos fundamentales que determinan el rol que la sociedad civil puede jugar en los procesos e integración. Son tres a su juicio: la existencia de propuestas claras; que deben llegar a los que deciden (parlamentos, empresarios, etc.); y para ello es necesario la movilización ciudadana. Para él, los procesos de integración no deberían subsumirse en los acuerdos económicos y comerciales, sino que deben alcanzar a la sociedad en su totalidad. Ve necesario un nuevo rol del Estado, de la Sociedad Civil y del sector privado.

21 Miami, 1994; Santa Cruz de Bolivia, 1996; Santiago de Chile, 1998; y Québec, 2001.

22 R. RuBio, www.bancomundial.org/foros (12/11/03). 
Para Katia Maia ${ }^{23}$ " "la integración debería tener otra concepción que sólo la del libre comercio. Los únicos beneficiados de los tratados de libre comercio son los exportadores y las grandes empresas. El objetivo principal de la integración debería ser combatir la desigualdad considerando las asimetrías estructurales existentes entre países que firman un acuerdo de integración". Afirma que los procesos de integración regional no han cumplido sus objetivos en América Latina, y finaliza solicitando al Banco Mundial -organizador del foro- ayuda para pensar nuevos modelos de integración.

Alfredo Manasoff ${ }^{24}$, Ministro de Trabajo de Argentina, aboga por el desafío de la profundización en la integración. Ve fundamental el papel de la sociedad civil, pero hay que generar mecanismos de participación y canalización de las demandas.

Álvaro Padrón ${ }^{25}$ se esfuerza en distinguir MERCOSUR y ALCA. Hace hincapié en los avances participativos de la sociedad civil en el MERCOSUR, y en sus beneficios:..."crea legitimidad, permite aumentar la calidad de las políticas y da estabilidad al proceso. Se trata de profundizar la democracia. La sociedad civil debe ubicarse escala regional si quiere ser un interlocutor válido. En estos doce años, la sociedad civil ha logrado influir en el proceso, pero esta influencia no ha sido suficiente. La participación es un arma de doble filo: por un lado es una oportunidad, por otro un desafío. Una vez se participa surge el compromiso".

Entre las conclusiones de este foro destacan las siguientes:

- La participación efectiva de la sociedad civil es condición indispensable en los procesos de integración regional. Debe ser una participación orgánica.

- No existe ningún programa de integración que por sí solo genere equidad social. Las políticas de integración deben generar estrategias para ello.

- Los sectores populares sólo pueden participar si están formados.

- Lagobernabilidad y la calidad política de la democracia es el fundamento esencial ${ }^{26}$.

23 K. MAIA, www.bancomundial.org/foros (15/11/03).

24 A. Manasoff, www.bancomundial.org/foros (15/11/03).

25 A. PADRón, www.bancomundial.org/foros (16/11/03).

${ }^{26}$ www.bancomundial.org/foros (19/11/03). 
El último foro de importancia se celebró en diciembre de 2003, en la ciudad de México, dentro del marco de la Cumbre Extraordinaria de las Américas celebrada en los primeros días de enero de 2004 en la también mexicana ciudad de Monterrey. Este foro regional, de gran repercusión, llevaba por título "La sociedad civil en los procesos de integración hemisférica". Sin embargo sus debates han girado en torno a problemas de mayor alcance, como pueden ser el crecimiento económico con equidad, el desarrollo social y la gobernabilidad democrática en los diferentes Estados. Entre estos temas, resaltaron la desilusión generada por los resultados limitados que la democracia ha venido ofreciendo en términos de beneficios económicos y sociales. Se reconoció asimismo un recrudecimiento de la pobreza y de la desigualdad.

Sus conclusiones más destacadas no hacen mención al avance de la integración regional, lo que nos ofrece otra visión diferenciada, en este caso enfatizando la relativa importancia que la sociedad civil otorga al asunto. Las principales son las que se enumeran:

- Se consideró positiva la creciente participación de las organizaciones de la sociedad civil en el proceso donde se establece la agenda hemisférica, aún cuando muchos gobiernos no están convencidos de la conveniencia de dicha participación, con especial mención al gobierno de México.

- La integración económica debe ayudar transformar las viejas estructuras económicas mediante la creatividad, la innovación, la educación, etc.

- En las negociaciones sociales el proceso de Cumbres, la participación de las organizaciones de la sociedad civil es amplia, reconocida y aceptada por los gobiernos, pero no sucede lo mismo en las negociaciones comerciales, coto cerrado de los gobiernos.

- Se subraya especialmente la importancia de la gobernabilidad democrática, instando a los gobiernos a solucionar las siguientes carencias: acceso a la información; libertad de expresión; descentralización y gobierno local; fortalecimiento de la sociedad civil; y acceso a la justicia ${ }^{27}$.

Una tercera plataforma de participación, la más novedosa e interesante, viene dada por la proliferación de páginas webs en internet que las numero-

${ }^{27}$ www.cumbresdelasamericas.org y en www.comormex.org (21/11/03). 
sas Asociaciones de la sociedad civil y organizaciones no gubernamentales creadas en la última década ponen a disposición de la ciudadanía. Constituyen un instrumento de gran valor al ofrecer un acceso rápido y eficiente a la información. Su enorme repercusión global es un elemento cohesionador al facilitar la interacción entre grupos diversos con afinidades ideológicas o reivindicativas. Es, por tanto, una herramienta dinámica activa que puede marcar una época por sus enormes posibilidades de comunicación y participación.

Son muy numerosas, destacando especialmente algunas que, por su calidad, diversidad y facilidad de acceso y participación, han servido de gran ayuda para la elaboración de este trabajo. Muy científica la de la Facultad Latinoamericana de Ciencias Sociales ${ }^{28}$; muy amplia la de la Fundación Canadiense para las Américas ${ }^{29}$; otras más reivindicativas, pero con una extensísima información, como Globalización América Latina, que incluye también a la organización Desarrollo, Economía, Ecología y Equidad de América Latina (D3e ${ }^{30}$; específica sobre el tema que nos ocupa es la de la Asociación Integración $\mathrm{Sur}^{31}$; y de fomento de la participación la chilena de la Corporación Participa $^{32}$. Todas ellas ofrecen una información extensísima y promueven la participación ciudadana, pudiendo encontrar expuesta toda la problemática actual que concierne directamente a ese continente.

\subsection{Acuerdos de integración regional vs. Tratados de libre comercio}

Aunque, por lo general, en el seno de las sociedades latinoamericanas ya nadie duda de las ventajas de la integración regional, corroborada y publicada por los diversos organismos de integración y por los diferentes representantes de los gobiernos latinoamericanos, éstas se vienen enfrentando -prácticamente desde los inicios del proceso integracionista- al dilema del modelo de integración más idóneo, a caballo entre una integración regional que profundice en los elementos comunes integradores o un tratado de libre comercio que se limite a la exención arancelaria.

\footnotetext{
28 www.flacso.org (20/11/03).

29 www.focal.ca $(21 / 11 / 03)$.

30 www.globalizacion.org (21/11/03).

31 www.integracionsur.com (20/11/03).

32 www.participa.cl (21/11/03).
} 


\section{GRÁFICO 2 \\ Volumen del comercio intracomunitario en las diferentes áreas de integración latinoamericanas}

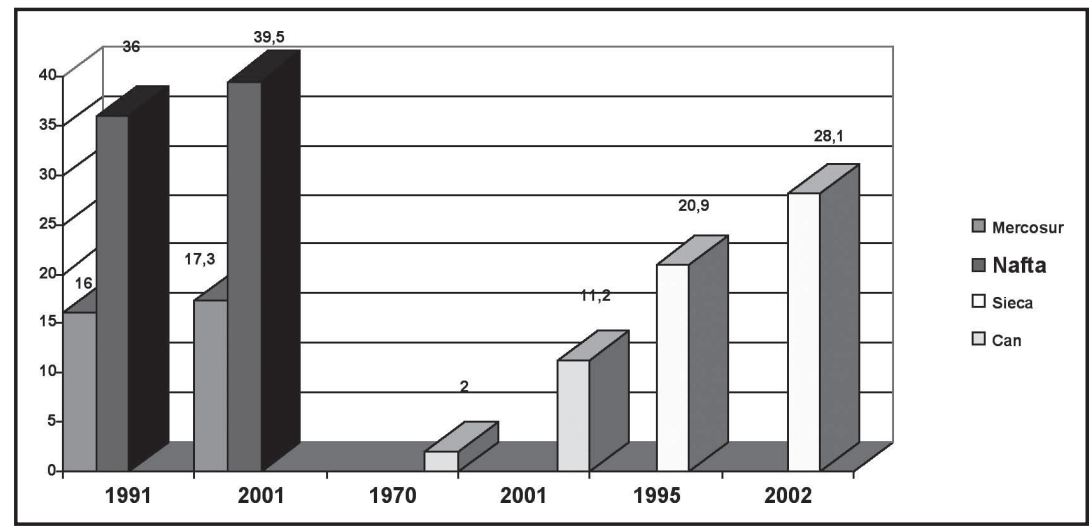

Fuentes: www.mercosur.org/uy. www.sieca.org. www.comunidadandina.org.

Existe confusión en la opinión pública entre el significado que posee la integración regional y el de los acuerdos de libre mercado. Esta confusión se propaga por diferentes medios, unas veces interesadamente y otras como efecto del desconocimiento que en algunos países existe de los procesos integradores.

Pero también tenemos una considerable porción de la sociedad civil en algunos países, aquella mejor formada, que participa en los movimientos sociales ciudadanos, que no sólo distingue entre un modelo y otro, sino que se encarga de difundir y ejercer de correa de transmisión de sus propuestas. Veamos.

En primer lugar nos encontramos con aquellos grupos interesados en ofrecer una imagen confusa de uno y otro modelo. Estos grupos suelen ser partidarios de los tratados de libre comercio, a ser posible bilaterales, sin ningún interés en la creación de zonas más amplias. Se suelen identificar con las clases industriales y agrarias de tradición exportadora, vinculados a las oligarquías nacionales, que anduvieron siempre cercanos a las fuentes de poder. Son contrarios a los procesos integradores que acarreen mayor participación y, en general, una profundización democrática, ya que pondrían 
en peligro sus tradicionales beneficios sociales: reforma fiscal, educación restringida, administración del Estado, etc. Al mismo tiempo, poseen los recursos y los resortes necesarios para transmitir sus mensajes, ya que tienen acceso a los medios de comunicación, los medios económicos -que controlan- y a los medios ejecutivos a través de los diferentes gobiernos locales, regionales o nacionales.

Otro elemento generador de confusión podríamos situarlo en la propia desinformación de las sociedades latinoamericanas. El interés y la información que generan los procesos de integración regional no son uniformes a lo largo y ancho de América Latina, aunque todos los países estén involucrados en ellos. Los argumentos ya se han mencionado aquí, y están directamente relacionados con su nivel de desarrollo. Las organizaciones de la sociedad civil tampoco se encuentran en todos los países con similares niveles de organización e información. Por consiguiente, encontramos algunas sociedades muy desinformadas que suelen ser presas fáciles de los intereses más poderosos, ya sean provenientes de los gobiernos o de los diversos grupos de presión. No se puede ocultar que la falta de información de los procesos integracionistas en países como Paraguay, Perú, Ecuador, Bolivia, El Salvador u Honduras, constituye un serio hándicap para el desarrollo de éstos. Por su perfil específico, son un caldo de cultivo perfecto para las distorsiones interesadas.

Al mismo tiempo, nos encontramos con la confusión que, a veces, generan las propias autoridades gubernamentales y las clases dirigentes, incluso desde de los mensajes lanzados por las instituciones, como, por ejemplo la declaración ministerial de la octava reunión del ALCA, que incluye a los tratados de libre comercio como un modelo de integración regional, en un claro intento de manipulación y confusión de la opinión pública.

Un elemento más a tener en cuenta en esta discordia se encuentra en el seno de los gobiernos de algunos países. La irrupción de la propuesta estadounidense de su área de libre comercio continental, ALCA, ha supuesto un freno a los diferentes procesos integradores en diversas repúblicas latinoamericanas. Es importante resaltar el hecho de que para muchos países, en especial aquellos que poseen mercados de dimensiones reducidas y elevados índices de dependencia económica, como por ejemplo los centroamericanos, el acceso a los mercados norteamericanos resulta fundamental. Las presiones estadounidenses han puesto de nuevo en duda a algunos gobiernos que en un principio apostaban por la integración y por la profundización de sus procesos hacia uniones aduaneras e incluso monetarias. 
En este sentido, cabe destacar las manifestaciones de Pablo Bergel, sindicalista uruguayo, que al hacer balance de una década de MERCOSUR, se queja de que éste se va a convertir en una mera área de Libre comercio, absorbido y disuelto en el ALCA. "En realidad no existe libre comercio, sino libertad de comercio entre grandes empresas, ya que las pequeñas apenas responden con un $2 \%$ del total...Cavallo ha derogado el Arancel externo Común, que definía hasta entonces al MERCOSUR como una unión aduanera. Responde así a la lógica de los grandes capitales, para nada interesados en la integración de naciones pueblos, con equidad distributiva, amplio mercado interno, fuerte protagonismo y participación de los sectores sociales, con una construcción institucional y política democrática y participativa, con una fuerte impronta de intercambio cultural y construcción de nuevas identidades regionales"33.

En el Tercer Foro temático regional "Integración con equidad" celebrado el pasado mes de octubre en Brasil, ya mencionado en este trabajo, se hizo énfasis en la diferenciación entre procesos de integración regional y tratados de libre comercio ${ }^{34}$. Igualmente se subrayó la interdependencia que se podría suscribir entre un modelo y otro, como por ejemplo desarrolla la Unión Europea, y de las ventajas que los acuerdos integracionistas suponen como posición de fuerza en la negociación de tratados bilaterales, como se ha puesto de manifiesto recientemente en la cumbre de Cancún.

En este aspecto es de resaltar la posición de las diferentes ONGs, claramente favorables a los procesos integracionistas conscientes de que dichos procesos serían los que verdaderamente podrían incidir directamente sobre la erradicación de la pobreza y el desarrollo. Mención aparte merecen aquellas organizaciones europeas que vienen trabajando en la cooperación y el desarrollo de Latinoamérica, denominadas ONGD, que suelen ver con cierta desconfianza dichos procesos.

Son estas mismas organizaciones no gubernamentales las que se esfuerzan en divulgar los beneficios de la profundización de los procesos de integración regional, como queda de manifiesto en la visita a cualquiera de sus órganos de difusión. En todas ellas se pone de manifiesto el momento crucial que se vive, ante la amenaza del ALCA, y la importancia que para América Latina tiene la profundización integradora, que traería consigo la solución paulatina de algunos de los más importantes aspectos de la agenda habitual

33 P. BERGEL, www.globalizacion.org (27/11/03).

34 A. PADRÓn, www.bancomundial.org/foros (27/11/03). 
de la sociedad civil latinoamericana, como puede ser la gobernabilidad, la profundización democrática, la erradicación del hambre, de la pobreza y de la desigualdad, la equidad distributiva, la construcción institucional o la participación de la ciudadanía.

El economista Eduardo Gudynas, en su documento "Nuevos agrupamientos en América Latina", resalta el fracaso de la cumbre de la Organización Mundial del Comercio de Cancún, que evidencia sus deficiencias y potenció el papel de las organizaciones ciudadanas. "Las circunstancias de América Latina siguen siendo muy complejas”. Aplaude el liderazgo brasileño ante los poderosos y su esfuerzo en sumar apoyos al MERCOSUR (incorporación de Perú, Bolivia y la probable de Venezuela). Pero advierte ante los peligros de esta fórmula de ampliación, que haría correr el peligro de la pérdida de calidad de la integración: "En el MERCOSUR no existen estrategias productivas comunes, por lo que varios países compiten entre ellos buscando exportar más o menos lo mismo. Muchos países, como los de Centroamérica, Ecuador, Colombia o Chile, conciben el ALCA como la mejor salida para sus dificultades. Con el ALCA, el proceso de integración regional vive horas difíciles, ya que sus socios mantienen fuertes divergencias, y los antídotos que ensayan, como la ampliación del MERCOSUR, no aseguran soluciones sustantivas. Así irán cayendo estrategias unilaterales poco a poco que harán perder cohesión a las posiciones latinoamericanas" 35 .

Para Jaime Estay, economista e la Universidad de Puebla, el ALCA fue el intento de ganar terreno perdido por parte de EEUU en una zona inmediata de su influencia, como respuesta a la fuerza de los movimientos de integración. Por medio del ALCA los países latinoamericanos están siendo objeto, una vez más, del "deber ser" dictado desde los EEUU... "Mientras el ALCA ha mantenido una marcha lenta, los países latinos y caribeños han continuado progresando en sus propios procesos de integración, tras los retrocesos de la crisis económica. Este nuevo impulso integrador, asume nuevas características...tiende a cambiar los grados de participación de gobiernos y empresarios, con una presencia reciente de los representantes de ambos actores; si bien los demás sectores de la población -y en particular los trabajadores- siguen teniendo un acceso restringido o nulo. La tónica general viene siendo limitar el esfuerzo integrador al sólo ámbito de la economía, y más concretamente, a los aspectos comerciales, dejando de lado otro tipo de vínculos políticos, culturales, etc. "36.

35 E. GUDYNAS, www.globalizacion.org (25/11/03).

36 J. EsTAY, www.ambiental.net (27/11/03). 
Denise Gorfinkiel y Eduardo Gudynas avisan del peligro de abandonar los procesos de integración por la opción del ALCA: "la visión tradicional de los acuerdos de libre comercio ha olvidado considerar los riesgos y vulnerabilidades que enfrentan los países de América Latina. Los que dependen excesivamente de la exportación de recursos naturales, mantienen altos niveles de pobreza ocarecen de una fuerte gestión ambiental son más vulnerables a los impactos negativos de la apertura comercial. Podríamos preguntarnos, entonces, cuál es la vulnerabilidad de los países latinoamericanos bajo este esquema comercial que promueve el ALCA. O en otras palabras: ¿cuál es la vulnerabilidad de cada país si el ALCA tiene éxito y se avanza por el camino de la desregulación comercial? Para evaluar estos problemas se presentó en la reunión ministerial de Miami una nueva versión del índice latinoamericano de vulnerabilidad ante el libre comercio (IVLC)"37. Este índice muestra la vulnerabilidad de las diferentes economías latinoamericanas con respecto a la acción de productos extranjeros en sus mercados. Un valor cero muestra la menor vulnerabilidad. En el siguiente gráfico se observa como la mayoría de las economías de América Latina son muy vulnerables ante la permeabilidad de los productos externos en sus mercados, con Nicaragua, Ecuador, Honduras, Paraguay y Guatemala como países más vulnerables.

\section{GRÁFICO 3 \\ Índice Latinoamericano de Vulnerabilidad Económica}

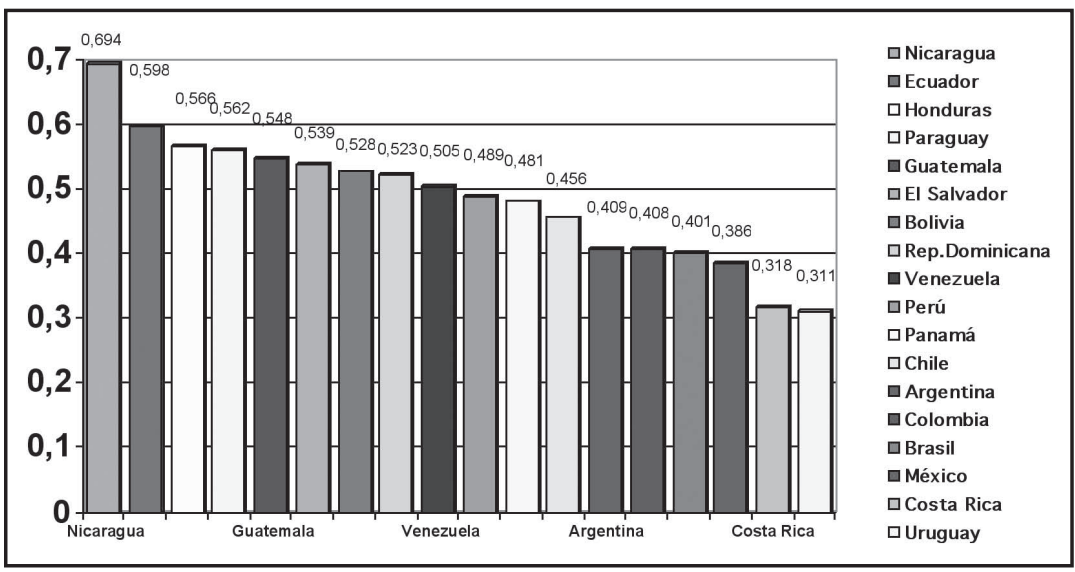

Fuente: Gudynas, E. www.redtercermundo.org.

37 D. GoRfinKIEl y E. GudYNAS, www.redtercermundo.org (26/11/03). 
En resumen, se advierte que determinados sectores de la sociedad civil latinoamericana confunde los acuerdos de integración regional con los tratados de libre comercio. Estos sectores se localizan en los países en los que los procesos integradores han alcanzado menores niveles de conocimiento y participación debido a la especial configuración de sus sociedades. En otros países más desarrollados, la sociedad civil entiende perfectamente la delimitación entre un modelo y otro. Sin embargo, están sometidos a otros tipos de distorsiones interesadas, como pueden ser las de sus propios gobiernos o la de diversos grupos de presión. Con el apoyo de las ONGs internacionales que actúan en diversos territorios latinoamericanos, se esfuerzan en difundir sus propuestas en la profundización de la integración regional de América Latina, conscientes de que sólo estos procesos generarán los beneficios sociales que conduzcan a un mayor desarrollo y a la erradicación de la pobreza y de la desigualdad, así como a la consecución de la mayoría de las reivindicaciones sociales durante tanto tiempo reclamadas.

De lo expuesto, podemos extraer una serie de conclusiones fundamentales, que reflejarían por un lado el estado actual de los procesos de integración regional en América Latina, y por otro, la posición desde la que la sociedad civil participa y se posiciona en estos procesos.

\section{Conclusiones}

$1^{a}$. Con respecto a los procesos de integración regional en América Latina, se puede constatar que éstos, lejos de constituir una novedad histórica, han conocido una dinámica revitalizadora iniciada en la década de los noventa como respuesta a la descomunal crisis de la década anterior. Pero como ya sucedió con sus precedentes, las expectativas integracionistas no han pasado del dicho al hecho, y aunque los resultados comerciales son satisfactorios en todos los casos, ninguno de los procesos ha avanzado en la constitución de una verdadera comunidad económica, quedándose en una mera zona de libre comercio.

$2^{a}$. La participación de la sociedad civil en estos nuevos procesos integradores ha sido muy escasa. Ello se debe fundamentalmente a las características estructurales de estas sociedades. A la complejidad intrínseca se ha unido un progresivo proceso de dualización económica, que ha configurado unas sociedades muy vulnerables y desvertebradas. Ello es fruto del modo específico de desarrollo económico latinoamericano, caracterizado por la impo- 
sición externa de un capitalismo limitado y dependiente con la connivencia de las clases dirigentes nacionales. No existe una organización social al uso, las clases sociales son muy débiles y están muy divididas. Su participación en la escena pública no ha existido habitualmente, respondiendo sólo a los llamamientos del Estado para su vinculación con intereses nacionales. Por otro lado, la crisis institucional permanente en la que se ven inmersos la mayoría de los Estados y la precariedad de los modelos sociales colocan en segundo plano la preocupación de estas sociedades por los procesos de integración regional, dando clara prioridad a la resolución de aquellos.

En la actualidad, la participación está resultando más numerosa y efectiva, favorecida por la aparición de nuevos actores sociales surgidos de los efectos globalizadores -tanto a nivel técnico como a nivel ideológico-y de la positiva evolución de los procesos democráticos, que si bien siguen conociendo períodos convulsos, se han visto favorecidos por la nueva configuración unipolar de la política internacional. No obstante, esta participación es todavía insuficiente, quedando algunos sectores al margen de la dinámica participativa, como puede ser la clase trabajadora, tanto la formal como la informal. No obstante, existen países en los cuales el desconocimiento de la ciudadanía de estos procesos integracionistas es muy elevado, por lo que su participación es casi nula. Entre todos ellos destacan especialmente Paraguay, Honduras o Panamá.

3 . Se advierte cierta confusión en el seno de la sociedad civil latinoamericana con respecto al significado que posee la integración regional y el de los acuerdos de libre mercado. Esta confusión se detecta, sobre todo, en aquellos países donde los procesos de integración han alcanzado menos desarrollo o en aquellos otros cuyas sociedades civiles apenas se han configurado. En este estado de cosas, la propuesta estadounidense del ALCA ha venido a complicar y a confundir más aún el panorama. La población se ha dividido entonces entre los que se oponen abiertamente a este proyecto-entre la que se halla aquella porción de la población con mayor implicación y participación, mejor informada-y los que no distinguen entre un proceso y otro.

Hasta ahora, las campañas lanzadas por aquellos grupos de la sociedad civil partidarios de la profundización integradora junto con los continuos mensajes de las organizaciones no gubernamentales de desarrollo presentes en la zona, así como la aparición de un liderazgo político afín en la figura del presidente brasileño Lula Da Silva, han conseguido frenar la firma de la propuesta estadounidense. Sus argumentos se fundamentan en la búsqueda 
de un modelo de desarrollo alternativo, que apueste por la persecución del bienestar mediante la desaparición del hambre y la pobreza, una mayor equidad en el reparto de la riqueza o la profundización de los procesos democratizadores que permitan una mayor participación de la ciudadanía en las políticas estatales, objetivos estos habituales en la agenda de la sociedad civil latinoamericana.

4 a . El remozado escenario sociopolítico gestado desde la década de los noventa y la globalización tecnológica han permitido la creación de nuevos espacios de debate y participación donde la sociedad civil puede manifestarse y hacer oír su voz, oficializados por los diferentes organismos internacionales. Estas flamantes plataformas de diálogo se han centrado en torno a las Cumbres de Jefes de Estado y a los Foros de debate, amén de un intenso intercambio de información y opiniones surgido en las páginas webs de las múltiples asociaciones y organizaciones creadas.

5 a . La sociedad civil mira con recelo y escepticismo hacia los procesos de integración sin que se la pueda culpar por ello, si tenemos en cuenta los antecedentes y lo poco que han variado los escenarios económicos, sociales y políticos. La propia configuración social de la mayoría de los países, el desencanto de la sociedad ante las continuas demostraciones de ineficacia e ineptitud de las elites gobernantes, la marginación de la intervención en los procesos y las continuas campañas de desprestigio lanzadas desde los sectores contrarios, son las causas principales de este recelo.

\section{Bibliografía}

Caldentey del Pozo, P., (2001), El desarrollo económico de Centroamérica en el Marco de la Integración Regional, Tegucigalpa, Edit. BCIE.

Calvo Hornero, A., (1994), Integración Económica y regionalismo, Madrid, Edit. Centro de Estudios Ramón Areces.

CEPAL, (1994), El regionalismo abierto en América Latina y el Caribe. La integración económica al servicio de la transformación productiva con equidad.

Cepal, (2003), Panorama social de América Latina 2002-2003.

Freres, Christian (coord.), (1997), La cooperación al desarrollo bilateral de la Unión Europea con América Latina, Madrid, AIETI

GRIEN, RAúl, (1994), La Integración económica como alternativa inédita para 
América Latina, México, Edit. Fondo de Cultura Económica.

Malamud, C.; Pardo, R y otros, (1995), Historia de América, Madrid, Edit. Universitas.

Malamud, C., (1995), América Latina, siglo XX. La búsqueda de la democracia, Madrid, Edit. Síntesis.

Monsivais, C., (2000), Aires de Familia. Cultura y Sociedades en América Latina, Madrid, Edit. Anagrama.

Murillo Viana, F., (1986), América Latina en los ochenta, Madrid, Edit. Cultura Hispánica, Instituto de Cooperación Iberoamericana.

Ortega Carpio, M. L., (1994), Las ONGD y la crisis del desarrollo, Madrid, Edit. IEPALA-ETEA.

REVISTA SIINTESIS, nº 24, Junio-Diciembre 1996.

Romero, J. J. y Rodero, A., (1999), España en la UE. Más allá del Euro, Córdoba, Edit. Publicaciones ETEA.

Salamon, A; Anheier, H. K.; List, R; Toepler, S.; Sokolowski, W.; y colaboradores, (2001), La sociedad civil global. Las dimensiones del sector no lucrativo, Fundación BBVA.

Torre, H. DE LA y Morales, V. (coord.), (1997), Historia Universal Contemporánea, Edit. Centro de Estudios Ramón Areces, $4^{a}$ Edic.

Touraine, A., (1989), América Latina. Política y Sociedad, Edit. Espasa Calpe.

VArios, (2000), El estado del mundo 2001. Anuario Geopolítico Económico Mundial, Madrid, Edit. Akal.

\section{Webs}

- Comunidad Andina de integración. www.comunidadandina.org.

- Diario Clarín de Buenos Aires. www.clarín.com/arg.

- Diario La Nación de Buenos Aires. www.lanacion.com/arg.

- Diario El Económico de Santiago de Chile. www.eleconomico.cl.

- Diario El Comercio de Quito. www.elcomercio.com.

- Banco Mundial. www.bancomundial.org. 
- Cumbres de las Américas. www.cumbresdelasamericas.org.

- Comité Organizador Mexicano de la Cumbre de las Américas. Monterrey 2004. www.commormex.org.

- Facultad Latinoamericana de Ciencias Sociales. www.flacso.org.

- ONG D3E (Desarrollo, Economía, Ecología y Equidad). www.globalización. org.

- ONG Integración Sur. www.integracionsur.com.

- ONG Participa. www.participa.cl.

- Mercosur. www.MERCOSUR.org/uy.

- Sistema de Integración Económica Centroamericana. www.sieca.org.

- ONG Centro Latinoamericano de Ecología Social. www.ambiental.net.

- ONG Red del Tercer Mundo. www.redtercermundo.org. 